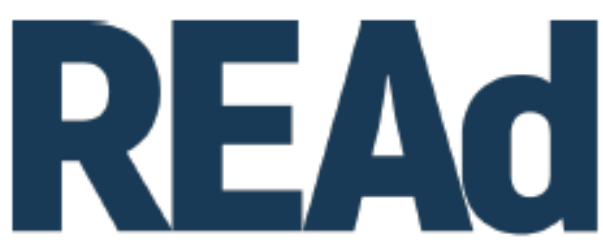

Revista Eletrônica de Administração

\title{
ANÁLISE DE UMA BASE DE DADOS INÉDITA SOBRE A FORMAÇÃO ACADÊMICA DOS DIRIGENTES DAS INSTITUIÇÕES FINANCEIRAS BRASILEIRAS ${ }^{1}$
}

\author{
Marcelo Pinho ${ }^{2}$ \\ Lucas Oishi Grigolin ${ }^{3}$ \\ João Vitor Carvalho Lopes ${ }^{4}$
}

http://dx.doi.org/10.1590/1413-2311.326.102658

\begin{abstract}
RESUMO
O perfil social dos dirigentes de empresas é um tema que interessa tanto às ciências sociais, em seus estudos sobre as elites, quanto à administração, que frequentemente busca vínculos entre o desempenho das firmas e características dos indivíduos que as dirigem. Este artigo almeja contribuir para ambos os campos de conhecimento analisando uma característica específica, a formação acadêmica nos níveis de graduação e pós-graduação, de um importante grupo social, os dirigentes de instituições financeiras brasileiras. Com esse propósito, foi construída uma base de dados sobre 1.016 indivíduos a partir de informações coletadas nos sites dessas empresas. Essa base cobre 19 bancos, inclusive os cinco maiores do País, e 65 instituições financeiras não bancárias. Entre os principais resultados, pode-se destacar: a proporção muito pequena (13\%) de mulheres; a baixa frequência (17\%) de dirigentes com cursos de pós-graduação stricto sensu; e a concentração (79\%) das graduações em três áreas de conhecimento (administração, economia e engenharia), em relativamente poucas instituições - metade das graduações em apenas seis instituições - e, mais ainda, em instituições de ensino localizadas no eixo Rio-São Paulo (81\% do total).
\end{abstract}

Palavras-chave: Elites. Governança corporativa. Setor financeiro no Brasil. Bancos no Brasil. Perfil dos dirigentes de empresas.

\section{ANALYSIS OF AN UNPUBLISHED DATABASE ON THE ACADEMIC FORMATION OF THE DIRECTORS OF BRAZILIAN FINANCIAL INSTITUTIONS}

\footnotetext{
${ }^{1}$ Recebido em 3/5/2020; aceito em 6/5/2021.

${ }^{2}$ Universidade Federal de São Carlos - Departamento de Engenharia da Produção; São Carlos - SP (Brasil); http://orcid.org/0000-0002-2733-5332; mpinho@ufscar.br.

${ }^{3}$ Universidade Federal de São Carlos - Departamento de Engenharia de Produção; São Carlos - SP (Brasil); http://orcid.org/0000-0002-1826-1597; lucasoishi@ gmail.com.

${ }^{4}$ Universidade Federal de São Carlos - Departamento de Engenharia de Produção; São Carlos - SP (Brasil); http://orcid.org/0000-0002-2674-2112; joaovlopes96@ gmail.com.
} 
The social profile of firms' top-managers is an issue that is of interest both for the social sciences, in the studies of elites, and management, which often search for links between the performance of companies and the characteristics of the individuals who run them. This article seeks to contribute to both fields of knowledge by analyzing a specific characteristic, academic education at the undergraduate and graduate levels, of an important social group, the heads of Brazilian financial institutions. For this purpose, a database on 1,016 individuals was built from information collected from their résumés published on the companies' websites. This base comprehends 19 banks, including the five largest in the country, and 65 non-bank financial institutions. Among the main results, we can highlight the very small proportion (13\%) of women; the low frequency (17\%) of top-managers with graduate courses; and the concentration $(79 \%)$ of degrees in three areas of knowledge (administration, economics, and engineering), in relatively few institutions - half of the degrees in only six institutions - and, even more, in educational institutions located on the states of Rio de Janeiro and São Paulo (81\% of the total).

Keywords: Elites. Corporate governance. Financial industry in Brazil. Banks in Brazil. Topmanagement profile.

\section{ANÁLISIS DE UNA BASE DE DATOS NO PUBLICADA SOBRE LA FORMACIÓN ACADÉMICA DE LOS DIRECTORES DE INSTITUCIONES FINANCIERAS BRASILEÑAS}

El perfil social de los altos directivos de las empresas es un tema de interés tanto para las ciencias sociales, en sus estudios sobre las élites, como a la gestión, que a menudo busca vínculos entre el desempeño de las empresas y las características de las personas que las dirigen. Este artículo busca contribuir a ambos campos del conocimiento mediante el análisis de una característica específica, la formación académica en los niveles de pregrado y posgrado, de un importante grupo social, los jefes de las instituciones financieras brasileñas. Para este propósito, se construyó una base de datos de 1.016 individuos a partir de la información recopilada en los sitios web de estas empresas. Esta base comprende 19 bancos, incluidos los cinco más grandes del país, y 65 instituciones financieras no bancarias. Entre los principales resultados, podemos destacar la muy pequeña proporción (13\%) de mujeres; la baja frecuencia (17\%) de gerentes con cursos de posgrado; y la concentración (79\%) de títulos en tres áreas de conocimiento (administración, economía e ingeniería), en relativamente pocas instituciones (la mitad de los títulos en solo seis instituciones) y, aún más, en instituciones educativas ubicadas en el eje RíoSão Paulo (81\% del total).

Palabras clave: Elites. Gobierno corporativo. Sector financiero en Brasil. Bancos en Brasil. Perfil de alta gerencia.

\section{INTRODUÇÃO}

O perfil social e demográfico dos quadros dirigentes das empresas é um tema importante para pelo menos duas áreas de conhecimento. Nas ciências sociais, a caracterização das elites interessa a historiadores, sociólogos e cientistas políticos, que não costumam discordar do 
postulado de que a maneira pela qual as elites se estruturam e reproduzem é uma das características definidoras de uma sociedade (ARON, 1950). Na administração e nas finanças, vertentes teóricas distintas, como a teoria da agência, a visão baseada em recursos e a teoria dos escalões superiores, têm destacado a importância da composição das direções das empresas na explicação de sua conduta e desempenho (JOHNSON et al., 2013).

Compartilhando essa avaliação sobre a importância da temática, este artigo tem por objetivo contribuir para a caracterização de um aspecto peculiar de uma categoria social específica: a formação acadêmica dos dirigentes de instituições financeiras brasileiras.

Estudos anteriores no Brasil se debruçaram sobre temáticas semelhantes, mas, até onde sabemos, nunca sobre esse objeto específico e tampouco seguindo os procedimentos metodológicos aqui adotados. De fato, desde os anos 1960 a literatura de cunho sociológico abordou, por meio de surveys sistemáticos baseados em entrevistas, a caracterização das elites econômicas e empresariais brasileiras (LOUREIRO; OLIVIERI, 2002; COSTA, 2014), mas aparentemente nenhum esforço desse tipo foi dedicado diretamente aos empresários do setor financeiro ${ }^{5}$. Por outro lado, é sem dúvida crescente a literatura que, no campo gerencial, trata dos efeitos de diferentes traços dos dirigentes sobre a performance das empresas. Esses estudos partem da caracterização dos conselhos de administração e, além da questão mais geral da influência de variadas características desses órgãos no desempenho das empresas (ANDRADE et al., 2009), examinam o impacto específico de certas variáveis como o capital social dos seus integrantes (ARANHA et al., 2016), a participação feminina (COSTA et al., 2019) e a presença de membros com carreiras políticas (CAMILO et al., 2012). Novamente, porém, não foi encontrado nenhum estudo desse tipo que abordasse especificamente o setor financeiro.

É, portanto, a essa lacuna da literatura que este estudo se dirige. Para fazê-lo, foi necessário construir uma base de dados própria. A partir de consultas aos sites das 247 instituições financeiras vinculadas à Anbima (Associação Brasileira das Entidades dos Mercados Financeiro e de Capitais), foram coletados todos os résumés dos dirigentes disponíveis nesses sites. A sistematização da informação disponível gerou uma base de dados sobre 1.016 dirigentes de instituições financeiras.

O propósito mais geral deste artigo é analisar os dados dessa base relativos à formação acadêmica desses indivíduos nos níveis de graduação e pós-graduação. Serão exploradas informações sobre as áreas de conhecimentos e as instituições de ensino, especificando sua

\footnotetext{
${ }^{5}$ Em sua tese de doutoramento em antropologia, Markowitz (2004) debruçou-se sobre os banqueiros, mas com uma perspectiva metodológica diferente concentrou-se nas trajetórias das famílias controladoras dos três maiores bancos privados do País naquele momento: Bradesco, Itaú e Unibanco.
} 
localização e vínculo institucional. Acredita-se que, além de contribuir para o debate acadêmico nos campos sociológico e administrativo, o artigo oferece aportes relevantes para vários agentes vinculados ao setor financeiro: os gestores de recursos humanos nas empresas do setor, as instituições de ensino voltadas à formação desses profissionais e, mais genericamente, todos os interessados em construir carreiras nesse setor.

Além desta introdução, o artigo é composto por quatro seções. A próxima apresenta uma breve revisão dos dois campos da literatura referidos acima. Na sequência, é apresentado um detalhamento dos procedimentos metodológicos adotados na construção da base de dados assim como uma descrição da cobertura dessa base. O tópico seguinte é o mais extenso e reporta os resultados da pesquisa. Por fim, a seção conclusiva recupera os resultados mais importantes, interpreta-os e, quando pertinente, contrasta-os com resultados de outros estudos.

\section{REVISÃO DA LITERATURA}

A literatura que aborda a caracterização das elites e dos quadros dirigentes de empresas tem duas vertentes claramente demarcadas. A primeira, de cunho sociológico, reconhece o papel fundamental de grupos sociais com posições privilegiadas nos processos políticos e sociais e enfoca, a partir de uma perspectiva histórica, a caracterização de frações dessas elites em sociedades específicas. A segunda, mais afim às áreas de finanças e administração, desdobrou-se dos estudos sobre governança corporativa e se concentra na avaliação do impacto sobre a conduta e o desempenho das organizações do perfil dos seus quadros dirigentes. Nesta seção, revisaremos alguns dos estudos dessas duas vertentes, priorizando aqueles que por sua metodologia ${ }^{6}$ ou por seu objeto ajudem a construir um quadro de referência para a temática central deste artigo, a formação acadêmica dos dirigentes de instituições financeiras no Brasil.

Estudos recentes ajudam a caracterizar aspectos importantes, inclusive a formação acadêmica, de algumas das categorias que integram as elites no Brasil. O Conselho Nacional de Justiça realizou em 2018 um levantamento sobre as características demográficas, sociais e profissionais dos juízes brasileiros e obteve resposta de 11.348 (62,5\%) dos 18.168 magistrados ativos naquele momento (CONSELHO NACIONAL DE JUSTIÇA, 2018). No tocante ao perfil demográfico, destacam-se, por divergirem de características majoritárias entre a população brasileiras, as porcentagens de $38 \%$ de mulheres e de $80 \%$ que se declaram brancos. No tocante

\footnotetext{
${ }^{6}$ Nos estudos sociológicos e políticos, é muito comum o uso do método prosopográfico. A prosopografia aborda longitudinalmente as trajetórias de vida e as carreiras de grupos de indivíduos pertencentes a algum grupo social (STONE, 2011). Ainda que a abrangência em termos numéricos e o nível de aprofundamento desses estudos sejam variáveis, o grau de detalhe faz com que frequentemente se restrinjam a um número limitado de indivíduos ou a pequenos grupos.
}

(c) (1) @ REAd | Porto Alegre - Vol. 27 - N. 2 - Maio / Agosto 2021 - p. 612-641. 
à formação acadêmica, 49\% se graduaram em universidades públicas, proporção um pouco menor do que a registrada no passado, mas muito superior à parcela dessas instituições no contingente de vagas dos cursos de direito ${ }^{7}$. Por outro lado, ainda que $69 \%$ dos juízes tenham declarado alguma formação em nível de pós-graduação, as proporções de cursos stricto sensu são bem inferiores: $16 \%$ de mestres e $5 \%$ de doutores.

Costa e Codato (2013) analisaram o perfil de 240 senadores que atuaram na câmara alta do Congresso Nacional entre 1986 e 2016. Apenas 24 eram mulheres ${ }^{8}$. Quanto ao nível de instrução, cabe ressaltar que 219 senadores (91\%) concluíram ao menos um curso superior. Entre os cursos de graduação, sobressaem o direito (75 senadores ou $31 \%$ do total) e, em proporção bem menor, engenharias (13\%), economia (10\%) medicina (9\%) e administração (9\%). Outro estudo que se debruçou também sobre os senadores da república, mas em período diferente (1989-2006), indica que pelo menos 36\% dos senadores com nível superior de instrução haviam concluído alguma pós-graduação, seja ela lato ou stricto sensu (ARAÚJO, 2011, p. 560).

Em estudo realizado há mais tempo e que se inseria dentro de uma preocupação mais ampla de entender a lógica do provimento político e da construção da carreira dos ocupantes dos postos mais elevados da burocracia federal dos cargos, Loureiro et al. (1998) abordaram a formação dos ocupantes dos três níveis mais altos (DAS-4, 5 e 6) de cargos em comissão no Ministério da Fazenda. Dados relativos a dezembro de 1997 sobre a titulação máxima de 233 profissionais indicam que $26 \%$ deles dispunham de cursos de especialização, $8 \%$ de mestrado e 7\% de doutorado (LOUREIRO et al., 1998, p. 62).

O Instituto Brasileiro de Governança Corporativa (IBGC) publicou em 2016 um relatório sobre o perfil dos conselhos de administração das empresas brasileiras de capital aberto (INSTITUTO BRASILEIRO DE GOVERNANÇA CORPORATIVA, 2016). Embora enfoque sobretudo características organizacionais dos conselhos como o número de integrantes, a duração dos respectivos mandatos e a acumulação de cargos com a diretoria executiva, o estudo permite também uma caracterização sumária dos indivíduos que atuam como conselheiros nessas empresas. Cobrindo conselhos de 339 empresas, identificou-se uma proporção de 7,9\% de mulheres entre os 2.244 conselheiros $^{9}$. O relatório traça também o perfil de formação dos

\footnotetext{
${ }^{7}$ Levantamento realizado em 2004 apontava que 52,7\% dos juízes brasileiros eram egressos de instituições públicas de ensino superior. Em contraste, no ano de 2006, 93,5\% das vagas dos cursos de direito eram oferecidas por instituições privadas (ALMEIDA, 2010, p. 80; RAMOS; CASTRO, 2019, p. 6).

${ }^{8} \mathrm{Na}$ mais recente legislatura, a proporção é um pouco maior: dos 81 senadores em exercício em 202011 (13,5\%) são mulheres (BOLDRINI, 2020).

${ }^{9}$ Nada menos que $62 \%$ das empresas não contavam com nenhuma mulher entre os membros do seu conselho de administração (IBGC, 2016, p. 19).
} 
conselheiros de acordo com suas áreas de graduação. Engenharias (27,6\%), administração $(21,4 \%)$, economia $(15,6 \%)$ e direito $(13,3 \%)$ são as formações encontradas mais frequentemente (INSTITUTO BRASILEIRO DE GOVERNANÇA CORPORATIVA, 2016, p. 19).

Em estudo que compara os mecanismos de reprodução das elites e as trajetórias sociais dos seus membros em alguns países europeus, Ellersgaard et al. (2012, p. 8-9) apresentam dados sobre a formação acadêmica de 100 dos principais executivos de empresas sediadas em cada um dos países. A agregação dos dados não favorece a comparação das áreas de graduação, mas o nível de instrução pode ser comparado. A proporção de executivos com doutorado é bem parecida em três países (6\% no Reino Unido, $8 \%$ na Dinamarca e 10\% na França), mas a de mestres varia bastante entre eles $(23 \%, 54 \% \text { e } 80 \% \text {, respectivamente })^{10}$.

Como destacam Johnson et al. (2013), na outra vertente, a dos estudos gerenciais, desde meados dos anos 70 tem se expandido a produção acadêmica sobre os efeitos não apenas da independência e do tamanho, mas também da composição dos conselhos de administração sobre o desempenho das empresas. Essa literatura aborda atributos muito variados dos conselhos que podem afetar o comportamento e a performance das empresas, cobrindo desde características demográficas (idade, gênero, etnia, heterogeneidade e educação) até elementos que compõem o "capital" humano (experiência e tempo no cargo) e o capital social (status prévio, relações pessoais com a direção executiva e relacionamentos políticos e com outras organizações). Particularmente influentes têm sido as abordagens fundadas na Upper Echelons Theory, que propõe que as características dos gestores influenciam as estratégias, a organização e o perfil das empresas, afetando, por conseguinte, seu desempenho (HAMBRICK; MASON, 1984). Na sequência, alguns desses estudos são resenhados.

Enfocando o efeito do grau de diversidade do conselho de administração, Anderson et al. (2011) procuraram mensurá-la em seis diferentes dimensões, três ocupacionais (educação, profissão e experiência) e três sociais (sexo, idade e etnia). Concluem que a heterogeneidade de background dos diretores pode resultar em um conselho com maior variedade de habilidades, talentos e capacidade de resolver problemas. A pesquisa aponta ainda que apesar de a diversidade trazer benefícios, um conselho muito heterogêneo também pode constituir um problema, uma vez que haverá um aumento do custo de comunicação e possivelmente

\footnotetext{
10 Os autores também apresentam dados para a Alemanha, mas neste caso a comparabilidade dos níveis de instrução, dadas as especificidades dos sistemas de titulação acadêmica, parece duvidosa: seriam $46 \%$ de executivos doutores e $36 \%$ de mestres. Note-se também que os dados de cada país referem-se a anos diferentes: Alemanha, 1995; França e Reino Unido, 1998; e Dinamarca, 2007.
} 
dificuldade de coordenação. Numa linha similar, Hagendorff e Keasey (2010) identificaram que a diversidade ocupacional, de idade e de tempo de mandato nos conselhos influencia positivamente a performance de bancos norte-americanos que se envolveram em processo de fusão ou aquisição. Não encontraram, porém, evidências na mesma direção a respeito da diversidade de gênero nem tampouco do nível de experiência prévia no setor bancário.

Num estudo empírico que cobriu não os membros do conselho, mas sim os executivos principais, Costa et al. (2018) analisaram a relação entre características dos gestores e o grau de aversão ao risco corporativo num conjunto de 1.045 empresas portuguesas. O estudo levou em consideração diversos fatores que caracterizam os executivos, como educação, sexo, tempo de mandato e idade, e através de análises de regressão múltipla inferiu como cada característica se relacionava à aversão ao risco, medida pela volatilidade do retorno dos ativos das firmas. Os autores concluíram que o tempo de mandato e a formação nas áreas de administração e direito são características negativamente relacionadas à propensão ao risco; em contrapartida, talvez contrariando o senso comum, idade e o sexo feminino seriam fatores positivamente associados à propensão ao risco.

A ampla revisão desse corpo de literatura realizada por Johnson et al. (2013) conclui que embora as pesquisas sobre características demográficas da diretoria das empresas habitualmente argumentem que essas características afetam a cognição e o processo decisório, não é possível encontrar na literatura nenhum relacionamento indisputável entre qualquer dessas características e o desempenho das firmas. Especificamente em relação ao aspecto que mais interessa a este artigo, a formação acadêmica dos dirigentes, artigos diferentes chegam a resultados contraditórios com respeito ao impacto tanto sobre o valor das empresas quanto seu esforço inovativo. Não obstante, Johnson et al. (2013, p. 240) recomendam que os estudos devem ser aprofundados, buscando relacionar a demografia dos dirigentes com eventos mais diretamente ligados à ação deles e menos contingentes a uma enorme variedade de outros fatores, como é o caso da performance das empresas em termos de rentabilidade. Sugerem também cuidado com problemas de mensuração e com o uso de indicadores sintéticos, que podem ocultar mais do que revelar.

\section{MÉTODOS E BASE DE DADOS}

Considerando a inexistência de qualquer fonte conhecida que reúna informações detalhadas sobre a formação acadêmica dos dirigentes das instituições financeiras (IF) brasileiras, a elaboração deste artigo teve que ser precedida pela construção de uma base de 
dados específica ${ }^{11}$. O ponto de partida foram os links no site da Anbima para os sites das empresas que a ela são associadas. Muitos dos sites dessas empresas, mas não todos, apresentam mini-currículos dos seus dirigentes. Esses résumés não são, naturalmente, padronizados e variam tanto em cobertura - em alguns casos, os dirigentes retratados incluem além dos principais executivos também os integrantes dos conselhos - quanto em extensão e variedade das informações. De todo modo, quando são apresentados, quase sempre cobrem informações básicas sobre a trajetória profissional dos profissionais e sua formação acadêmica nos níveis de graduação e pós-graduação.

Durante o mês de abril de 2019, foram consultados os sites das 247 associadas à Anbima listadas no site da associação. Em 82 delas, havia résumés dos dirigentes. Para assegurar uniformidade na cobertura temporal, as informações foram baixadas e arquivadas para processamento posterior. Durante esse processamento, percebeu-se que o levantamento não havia alcançado os dois maiores bancos privados do país, o Itaú e o Bradesco. Uma busca adicional foi realizada em agosto e setembro de 2019 para cobrir essa lacuna, de tal modo que foram obtidas informações sobre os dirigentes de 84 IF, cerca de um terço das empresas associadas à Anbima. Não há nenhuma garantia de que esse subconjunto constitua uma amostra estatisticamente representativa do conjunto das associadas, mas não há nele nenhum viés de composição evidente e, como se verá a seguir, estão representadas na base de dados empresas de diferentes portes, segmentos de mercado e perfis em termos de controle do capital.

O passo seguinte na construção das bases foi transcrever as informações numa base de dados organizada numa planilha eletrônica. Nessa base, os dados estão organizados em doze campos de informação diferentes: (1) nome do dirigente; (2) gênero; (3) cargo executivo; (4) cargo no conselho; (5) nome da IF; (6) formações de graduação; (7) instituições de graduação; (8) formações de pós-graduação stricto sensu; (9) instituições de graduação stricto sensu; (10) formações de pós-graduação lato sensu; (11) instituições de graduação lato sensu; e (12) empresas em que teve experiência profissional anterior. Neste artigo, serão explorados os dados dos primeiros 11 campos.

$\mathrm{Na}$ transcrição e posterior verificação dos dados foi feito um grande esforço para padronizar certas informações de maneira a viabilizar as agregações a serem feitas na fase de análise. Foram uniformizadas as designações de cursos - economia no lugar de ciências econômicas, contabilidade no de ciências contábeis etc. - e das instituições de ensino superior

\footnotetext{
11 Neste sentido, ao basear-se em uma "lista focada", esta pesquisa se insere em uma das perspectivas metodológicas que Cousin et al. (2018) propuseram, em um recente artigo de revisão, como uma das direções indicadas para aprofundar e desdobrar os estudos sobre as elites.
} 
(IES). Além disso, novamente com o propósito de instrumentalizar a análise, foram construídas duas bases de dados auxiliares para caracterizar as IF e as IES. No primeiro caso, foram registradas para cada IF (1) a unidade da federação em que se situa a sede, (2) a natureza do controle do capital (estatal nacional, privado nacional ou estrangeiro), (3) a soma dos recursos sob sua gestão - no caso dos bancos, o valor do ativo total e no das gestoras de recursos, o patrimônio líquido dos seus fundos de investimento ${ }^{12}$ - e (4) o tipo de instituição, com uma divisão em duas categorias, bancos ou instituições financeiras não bancárias (IFNB). Já no caso das IES, foram registradas informações sobre (1) localização, (2) natureza do seu vínculo institucional (de um lado, pública ou privada e, de outro, nacional ou estrangeira) e (3) nota no Índice Geral de Cursos, instrumento de avaliação do Ministério da Educação para as IES brasileiras.

Cabe adiantar, desde logo, que apesar dos esforços supracitados, nem sempre foi possível detalhar todas as informações sobre as IES. Algumas já fecharam as portas ou mudaram de nome e não foi possível identificar sua localização ou vínculo institucional. Muito mais frequentemente, a informação publicada pelas IF nos résumés dos dirigentes era incompleta, não especificando em qual unidade de uma determinada instituição estudou o dirigente. Há, portanto, algumas lacunas de informação que resultarão, mais adiante, em diferentes números de observações pertinentes a cada atributo analisado.

A abrangência da base de dados pode ser resumida na Tabela 1. Ao todo, foram cobertas 84 IF, das quais 19 são bancos, inclusive os cinco maiores do País, e 65 IFNB (63 gestoras de recursos e duas securitizadoras). Os recursos geridos por essas instituições somavam $\mathrm{R} \$ 7,95$ trilhões. As IFNB são mais numerosas, porém têm um porte médio, segundo esse critério, 25 vezes menor. Por outro lado, são 1.016 os dirigentes com informações registradas na base de dados. A pequena proporção de mulheres chama imediatamente a atenção: $13 \%$ no conjunto das IF, $16 \%$ nas IFNB e apenas $9 \%$ nos bancos.

Tabela 1 - Caracterização da Base de Dados sobre a Formação Acadêmica de Dirigentes de IF

\begin{tabular}{l|r|r|r}
\hline \multicolumn{1}{c|}{ Discriminação } & \multicolumn{1}{|c|}{ Total } & \multicolumn{1}{c}{ IFNB } & \multicolumn{1}{c}{ Bancos } \\
\hline Instituições & 84 & 65 & 19 \\
Dirigentes & 1.049 & 631 & 418 \\
Homens & 914 & 533 & 381 \\
Mulheres & 135 & 98 & 37 \\
Recursos Geridos (R\$ bilhões) - Total & $7.950,3$ & 937,9 & $7.012,3$ \\
Recursos Geridos (R\$ bilhões) - Média por IF & 94,6 & 14,4 & 369,1 \\
\hline
\end{tabular}

Fontes: Elaboração própria a partir da base de dados, Valor1000 (edição de 2019) e Anbima. Ver rodapé 12.

\footnotetext{
12 Para os bancos, os valores foram obtidos na edição de 2019 da publicação Valor 1000. A única exceção foi o Banco Paulista, que não foi coberto por aquele levantamento e cujo valor do ativo foi consultado diretamente dos seus demonstrativos contábeis. Já no caso das IFNB, o patrimônio líquido dos fundos que elas administram foi consultado no próprio site da Anbima, mais especificamente nas tabelas que reportam o ranking dos gestores.
} 


\section{ANÁLISE DOS DADOS}

Esta seção explora as informações sobre a formação acadêmica dos dirigentes das instituições financeiras brasileiras que podem ser retiradas da base de dados descrita no tópico precedente. Em cada caso, além de informações sobre o conjunto das IF presentes na base, serão analisados também os dados de dois segmentos em que o setor pode ser dividido: os bancos e as instituições financeiras não bancárias. A análise principia pela formação em nível de graduação e depois alcança a pós-graduação stricto sensu e lato sensu. Cada nível de formação será tratado em um subitem específico, o qual abordará sucessivamente as áreas de conhecimento, as instituições de ensino superior (IES) mais destacadas, o vínculo institucional dessas IES e sua localização.

\subsection{FORMAÇÃO DE GRADUAÇÃO}

A Tabela 2 resume as informações sobre as áreas de conhecimento em que se formaram os dirigentes de IF retratados na base de dados. São ao todo 1.012 cursos de graduação, 612 de dirigentes de IFNB e 403 de bancos. Esses números não devem ser confundidos com os de dirigentes, já que a base não dispõe de informação sobre a formação de graduação de 59 dirigentes de IF, mas, em contrapartida, 57 dirigentes informaram em seus résumés duas graduações e um deles, três graduações.

Tabela 2 - Áreas de Conhecimento das Graduações dos Dirigentes de IF Brasileiras

\begin{tabular}{|c|c|c|c|c|c|c|c|c|c|}
\hline \multirow[b]{2}{*}{ Área de Conhecimento } & \multicolumn{3}{|c|}{ Total } & \multicolumn{3}{|c|}{ IFNB } & \multicolumn{3}{|c|}{ Bancos } \\
\hline & $\mathrm{N}$ & Freq. & Freq. Ac. & $\mathrm{N}$ & Freq. & Freq. Ac. & $\mathrm{N}$ & Freq. & Freq. Ac. \\
\hline Administração & 282 & $27,8 \%$ & $27,8 \%$ & 138 & $23,1 \%$ & $23,1 \%$ & 144 & $35,7 \%$ & $35,7 \%$ \\
\hline Economia & 276 & $27,2 \%$ & $55,0 \%$ & 184 & $30,8 \%$ & $53,8 \%$ & 92 & $22,8 \%$ & $58,6 \%$ \\
\hline Engenharia & 239 & $23,5 \%$ & $78,5 \%$ & 175 & $29,3 \%$ & $83,1 \%$ & 64 & $15,9 \%$ & $74,4 \%$ \\
\hline de Produção & 84 & $8,3 \%$ & $\ldots$ & 70 & $11,7 \%$ & $\ldots$ & 14 & $3,5 \%$ & ... \\
\hline Elétrica/Eletrônica & 41 & $4,0 \%$ & $\ldots$ & 25 & $4,2 \%$ & $\ldots$ & 16 & $4,0 \%$ & ... \\
\hline Civil & 34 & $3,3 \%$ & $\ldots$ & 20 & $3,3 \%$ & $\ldots$ & 14 & $3,5 \%$ & ... \\
\hline Mecânica & 33 & $3,3 \%$ & $\ldots$ & 24 & $4,0 \%$ & $\ldots$ & 9 & $2,2 \%$ & ... \\
\hline Outras & 47 & $4,6 \%$ & $\ldots$ & 36 & $6,0 \%$ & $\ldots$ & 11 & $2,7 \%$ & ... \\
\hline Direito & 82 & $8,1 \%$ & $86,6 \%$ & 37 & $6,2 \%$ & $89,3 \%$ & 45 & $11,2 \%$ & $85,6 \%$ \\
\hline Contabilidade & 55 & $5,4 \%$ & $92,0 \%$ & 26 & $4,3 \%$ & $93,6 \%$ & 29 & $7,2 \%$ & $92,8 \%$ \\
\hline TI, Computação e Sistemas & 22 & $2,2 \%$ & $94,2 \%$ & 8 & $1,3 \%$ & $95,0 \%$ & 14 & $3,5 \%$ & $96,3 \%$ \\
\hline Outros Cursos & 59 & $5,8 \%$ & $100,0 \%$ & 44 & $5,0 \%$ & $100,0 \%$ & 15 & $3,7 \%$ & $100,0 \%$ \\
\hline
\end{tabular}

Fonte: Elaboração própria.

Apesar de ser grande o número de diferentes cursos de graduação na base (79), três áreas com pesos semelhantes entre si concentram quase quatro quintos de todas as graduações de 
dirigentes de IF: administração (28\%), economia (27\%) e engenharias $(24 \%)^{13}$. Outras áreas que também se destacam, embora em proporção bem inferior, são o direito, a contabilidade e um conjunto de graduações na área de Tecnologia de Informação ${ }^{14}$. Nenhum outro curso de graduação alcança o limiar de $1 \%$ das formações encontradas na base de dados.

Essas três áreas são as mais importantes tanto para os bancos presentes na base de dados quanto para as IFNB, mas as proporções e as hierarquias são distintas nesses dois subconjuntos. Nas IFNB, a participação de administradores (23\%) é menor e predominam as graduações em economia (31\%) e engenharia (29\%). Sobressai, em particular, a presença de engenheiros de produção (12\%). Nos bancos, por outro lado, a graduação em administração alcança uma parcela bem maior $(36 \%)$, sendo em contrapartida menor, sobretudo, a participação das engenharias $(16 \%)$.

O levantamento de dados permitiu identificar em quais IES foram obtidas 957 das 1.015 graduações reportadas anteriormente. As principais informações pertinentes são sintetizadas na Tabela A.1 em anexo. Cabe reiterar que a essas 957 graduações não corresponde igual número de dirigentes de IF, já que alguns deles se graduaram mais de uma vez. Ainda que o número absoluto de instituições em que se formaram os dirigentes de IF, 189, não seja pequeno, é perceptível a concentração dessas graduações em um número muito menor de $\mathrm{IES}^{15}$. Para o conjunto das IF, metade das graduações foram obtidas em apenas seis IES e as 20 IES que lideram o ranking respondem por $69 \%$ do total. Essa concentração, no entanto, não é homogênea nos dois segmentos que integram o setor financeiro. No segmento das IFNB, a concentração é maior: as quatro IES líderes emitiram metade dos diplomas e as 20 principais, $82 \%$. Entre os bancos, é preciso reunir 14 IES para atingir o patamar de metade das graduações e as 20 mais destacadas não superam $59 \%$ do total.

Semelhantemente ao que se observou no tocante ao grau de concentração, não são muito grandes as diferenças nos rankings das IES do conjunto de IF e IFNB. Em ambos os casos, Puc-

\footnotetext{
${ }^{13}$ Essas áreas foram definidas a partir da agregação de cursos com designações diferentes, mas que claramente concentram-se em uma dessas três áreas de conhecimento. Assim, "economia" inclui, além de economia e ciências econômicas, alguns cursos de economia e finanças, economia empresarial e controladoria; e "administração" inclui, além de administração de empresas, cursos de administração pública e algumas modalidades especializadas de administração (por exemplo, de negócios, para bancários e com ênfase em comércio exterior) e gestão (financeira, de negócios e de pessoas). Por sua vez, "engenharia de produção" cobre, além de engenharia de produção, engenharia industrial.

14 Foram reunidos nessa categoria os seguintes cursos: ciência da computação, tecnologia da informação, processamento de dados, análise de sistemas, tecnologia em processamento de dados e informática. Se a engenharia da computação for também incluída nessa categoria, sua participação nas formações de graduação do conjunto dos dirigentes de IF subiria para 3,0\% (2,3\% nas IFNB e 4,0\% nos bancos).

${ }^{15}$ A maioria (116) das IES encontradas na base foi referida como instituição de graduação por apenas um dirigente de IF.
} 
Rio, USP, UFRJ e FGV são as quatro IES que mais formaram dirigentes de IES. No caso dos bancos, porém, as diferenças são significativas. Além da liderança pronunciada da USP, percebe-se que neste caso um conjunto de IES privadas paulistas (PUC-SP, FAAP, Unip, Mackenzie e FMU) assume maior importância (Tabela A.1).

O próximo atributo analisado das graduações dos dirigentes de IF é o vínculo institucional das instituições de ensino, que será combinado à sua localização no Brasil ou no exterior (Tabela 3). Nota-se, de imediato, que a esmagadora maioria dos dirigentes de IF graduou-se em instituições de ensino brasileiras (95\% das graduações). Para o conjunto dos dirigentes de IF, embora seja expressiva a parcela de graduações em IES públicas brasileiras $(36 \%)^{16}$, as graduações em IES privadas brasileiras predominam amplamente, com $60 \%$ do total ${ }^{17}$. De todo modo, o perfil das IES privadas em que eles se graduaram é bem diferente daquele que prevalece no sistema de ensino superior brasileiro. Avultam em importância as graduações em instituições confessionais e, em particular, em universidades católicas. Estão presentes na base de dados 190 graduações em pontifícias universidades católicas localizadas no Brasil, quase $20 \%$ do total. Por outro lado, cabe destacar que neste âmbito não há diferença digna de nota entre os dirigentes de bancos e de IFNB.

Em 848 graduações, foi possível detalhar a localização da IES. Esse número é menor do que nas duas tabelas anteriores porque não são incomuns as situações em que os dados originais não especificam a unidade da IES em que o dirigente se graduou. Isso ocorreu mais frequentemente com a FGV (53 referências sem especificação), mas foi observado também no caso do Ibmec (15 referências não especificadas) e algumas outras IES.

\footnotetext{
${ }^{16}$ De toda maneira, a proporção das IES públicas nas graduações dos dirigentes de IF cursadas no Brasil $(35,6 \%)$ parece superar a participação das IES públicas no número de alunos concluintes de graduações no conjunto das três áreas principais para a formação desses dirigentes (administração, economia e engenharias). Ao menos é o que se pode se pode inferir dos dados que o INEP (Instituto Nacional de Estudos e Pesquisas Educacionais Anísio Teixeira) publica nas Sinopses Estatísticas da Educação Superior. A edição mais antiga disponível refere-se ao ano de 1994 e aponta uma parcela de 32,4\% das IES públicas nos concluintes desses cursos; a mais recente, referente a 2018, indica que essa parcela caiu para 17,4\%. Cf. INEP (1995) e INEP (2019).

${ }^{17}$ Ao contrário, no caso das graduações no exterior são mais numerosas as universidades públicas.
} 
Tabela 3 - Vínculo Institucional das IES em que se Formaram os Dirigentes de IF Brasileiras

\begin{tabular}{|c|c|c|c|c|c|c|}
\hline \multirow[b]{2}{*}{ Discriminação } & \multicolumn{2}{|c|}{ Total } & \multicolumn{2}{|c|}{ IFNB } & \multicolumn{2}{|c|}{ Bancos } \\
\hline & $\mathrm{N}$ & Part. $\%$ & $\mathrm{~N}$ & Part. $\%$ & $\mathrm{~N}$ & Part. $\%$ \\
\hline Graduação & & & & & & \\
\hline Pública & 369 & $38,6 \%$ & 222 & $38,3 \%$ & 147 & $39,0 \%$ \\
\hline no Brasil & 341 & $35,6 \%$ & 205 & $35,3 \%$ & 136 & $36,1 \%$ \\
\hline no Exterior & 28 & $2,9 \%$ & 17 & $2,9 \%$ & 11 & $2,9 \%$ \\
\hline Privada & 588 & $61,4 \%$ & 358 & $61,7 \%$ & 230 & $61,0 \%$ \\
\hline no Brasil & 572 & $59,8 \%$ & 349 & $60,2 \%$ & 223 & $59,2 \%$ \\
\hline no Exterior & 16 & $1,7 \%$ & 9 & $1,6 \%$ & 7 & $1,9 \%$ \\
\hline Brasileira & 913 & $95,4 \%$ & 554 & $95,5 \%$ & 359 & $95,2 \%$ \\
\hline Estrangeira & 44 & $4,6 \%$ & 26 & $4,5 \%$ & 18 & $4,8 \%$ \\
\hline Pós-Graduação Stricto Sensu & & & & & & \\
\hline Pública & 70 & $36,3 \%$ & 42 & $31,6 \%$ & 28 & $46,7 \%$ \\
\hline no Brasil & 50 & $25,9 \%$ & 31 & $23,3 \%$ & 19 & $31,7 \%$ \\
\hline no Exterior & 20 & $10,4 \%$ & 11 & $8,3 \%$ & 9 & $15,0 \%$ \\
\hline Privada & 123 & $63,7 \%$ & 91 & $68,4 \%$ & 32 & $53,3 \%$ \\
\hline no Brasil & 94 & $48,7 \%$ & 75 & $56,4 \%$ & 19 & $31,7 \%$ \\
\hline no Exterior & 29 & $15,0 \%$ & 16 & $12,0 \%$ & 13 & $21,7 \%$ \\
\hline Brasileira & 144 & $74,6 \%$ & 106 & $79,7 \%$ & 38 & $63,3 \%$ \\
\hline Estrangeira & 49 & $25,4 \%$ & 27 & $20,3 \%$ & 22 & $36,7 \%$ \\
\hline Pós-Graduação Lato Sensu & & & & & & \\
\hline Pública & 95 & $16,3 \%$ & 43 & $17,0 \%$ & 52 & $15,8 \%$ \\
\hline no Brasil & 71 & $12,2 \%$ & 26 & $10,3 \%$ & 45 & $13,6 \%$ \\
\hline no Exterior & 24 & $4,1 \%$ & 17 & $6,7 \%$ & 7 & $2,1 \%$ \\
\hline Privada & 488 & $83,7 \%$ & 210 & $83,0 \%$ & 278 & $84,2 \%$ \\
\hline no Brasil & 389 & $66,7 \%$ & 164 & $64,8 \%$ & 225 & $68,2 \%$ \\
\hline no Exterior & 99 & $17,0 \%$ & 46 & $18,2 \%$ & 53 & $16,1 \%$ \\
\hline Brasileira & 465 & $79,1 \%$ & 191 & $75,2 \%$ & 274 & $82,0 \%$ \\
\hline Estrangeira & 123 & $20,9 \%$ & 63 & $24,8 \%$ & 60 & $18,0 \%$ \\
\hline
\end{tabular}

Fonte: Elaboração própria.

Fica patente o predomínio absoluto do chamado eixo Rio-São Paulo: considerando o conjunto dos dirigentes de IF, $81 \%$ das graduações foram obtidas em IES localizadas em um dos dois estados ${ }^{18}$. Embora o predomínio dessas IES esteja presente nas duas partes em que neste estudo o setor financeiro é segmentado (Figura 1), é nitidamente mais amplo entre as IFNB - alcança aqui $89 \%$ - do que entre os bancos (70\%). Vale registrar também a posição diferente das IES do Rio de Janeiro e de São Paulo nos dois segmentos. Se entre os bancos as graduações em instituições paulistas são quase cinco vezes mais numerosas, entre as IFNB, predominam as IES fluminenses. Por sua vez, as graduações em IES estrangeiras, como já se disse, são pouco frequentes, situando-se em torno de $5 \%$ do total no conjunto das IF e em seus

1811 das 84 empresas cujos dirigentes são retratados na base de dados têm sede fora do eixo Rio-São Paulo. Dessas 11, 8 têm controle estatal. 
dois segmentos. Acrescente-se apenas que, entre estas graduações no exterior, sobressaem as obtidas nos EUA ${ }^{19}$.

Figura 1 - Distribuição Geográfica das IES de Graduação dos Dirigentes de IF Brasileiras

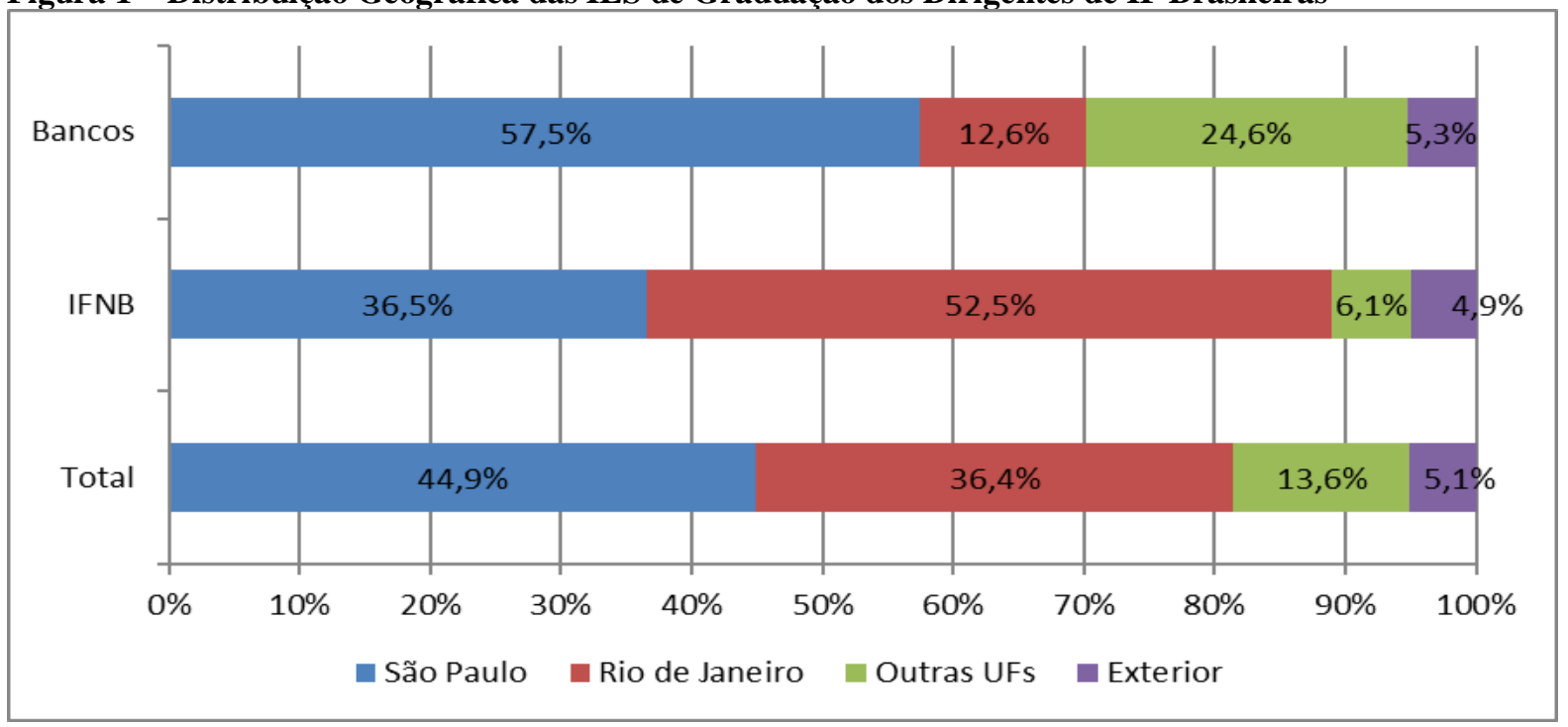

Fonte: Elaboração própria.

A concentração das graduações não transparece somente no âmbito geográfico ou, como se viu antes, das IES. Dentro destas, um punhado de cursos concentra boa parte das formações dos dirigentes das IF brasileiras. Com efeito, cerca de $40 \%$ das graduações se deram em dez cursos de seis IES (Tabela 4). Ademais, repetindo padrão identificado em outros aspectos, a concentração das graduações em relativamente poucos cursos é maior no caso dos dirigentes de IFNB do que no dos bancos. Entre aqueles, os dez cursos com maior número de graduações respondem por metade do total, ao passo que entre estes essa proporção cai para $27 \%$.

Tabela 4 - Escolas e Cursos mais Destacados na Graduação de Dirigentes de IF Brasileiras

\begin{tabular}{|c|c|c|c|c|c|c|c|c|}
\hline \multicolumn{3}{|l|}{ Total } & \multicolumn{3}{|l|}{ IFNB } & \multicolumn{3}{|l|}{ Bancos } \\
\hline IES/Área & $\mathrm{N}$ & Part. \% & IES/Área & $\mathrm{N}$ & Part. \% & IES/Área & $\mathrm{N}$ & Part. \% \\
\hline USP/Engenharia & 69 & $7,2 \%$ & PUC-Rio/Engenharia & 54 & $9,3 \%$ & USP/Engenharia & 26 & $6,9 \%$ \\
\hline PUC-Rio/Engenharia & 59 & $6,2 \%$ & PUC-Rio/Economia & 54 & $9,3 \%$ & FGV/Administração & 14 & $3,7 \%$ \\
\hline PUC-Rio/Economia & 58 & $6,1 \%$ & USP/Engenharia & 43 & $7,4 \%$ & USP/Economia & 11 & $2,9 \%$ \\
\hline FGV/Administração & 51 & $5,3 \%$ & FGV/Administração & 37 & $6,4 \%$ & PUC-SP/Administração & 9 & $2,4 \%$ \\
\hline USP/Economia & 30 & $3,1 \%$ & UFRJ/Engenharia & 28 & $4,8 \%$ & FAAP/Administração & 9 & $2,4 \%$ \\
\hline UFRJ/Engenharia & 30 & $3,1 \%$ & UFRJ/Economia & 21 & $3,6 \%$ & ITA/Engenharia & 8 & $2,1 \%$ \\
\hline UFRJ/Economia & 27 & $2,8 \%$ & USP/Economia & 19 & $3,3 \%$ & USP/Administração & 7 & $1,9 \%$ \\
\hline ITA/Engenharia & 19 & $2,0 \%$ & Ibmec-Rio/Economia & 15 & $2,6 \%$ & FEI/Engenharia & 7 & $1,9 \%$ \\
\hline FAAP/Administração & 17 & $1,8 \%$ & Candido Mendes/Economia & 14 & $2,4 \%$ & UFRJ/Economia & 6 & $1,6 \%$ \\
\hline PUC-Rio/Administração & 16 & $1,7 \%$ & PUC-Rio/Administração & 12 & $2,1 \%$ & PUC-SP/Economia & 6 & $1,6 \%$ \\
\hline Top-10 & 376 & $39,3 \%$ & Top-10 & 297 & $51,2 \%$ & Top-10 & 103 & $27,3 \%$ \\
\hline
\end{tabular}

Fonte: Elaboração própria.

19 Após as 17 graduações obtidas nos EUA, destaca-se a Espanha com sete graduações, das quais cinco correspondem a dirigentes de um único banco controlado por capital espanhol. 
Nota: No conjunto das IF, há mais um curso com 16 graduações: economia na Universidade Cândido Mendes. Do mesmo modo, considerando os dirigentes dos bancos, contam-se seis graduações também na administração da Unip.

\subsection{FORMAÇÃO DE PÓS-GRADUAÇÃO STRICTO SENSU}

O levantamento de dados permitiu identificar 196 formações de pós-graduação stricto sensu, das quais 175 em nível de mestrado e 21 em nível de doutorado. Como alguns poucos indivíduos reportaram em seus résumés mais de um curso nesses níveis, o número de dirigentes que informaram haver cursado pós-graduação stricto sensu é um pouco menor. 20 deles apresentam títulos de doutor e 171, títulos de mestre. Como três dos 20 doutores não indicaram um mestrado, pode-se inferir um total de 174 dirigentes (17\%) com alguma formação nesse nível de pós-graduação ${ }^{20}$.

O número de doutorados encontrados na base de dados é pequeno: 21. Destes, 12 são doutores em economia, distribuindo-se os nove outros por várias outras formações. Considerando o baixo número de doutorados, optou-se por analisar os dados relativos às pósgraduações stricto sensu sem discriminar as informações por nível de ensino.

Ressalte-se, antes de mais nada, que as três áreas mais destacadas na graduação são também as mais importantes na pós stricto sensu (Tabela 5) A hierarquia entre elas, no entanto, se altera e, no conjunto das IF, o peso da economia se torna muito maior do que os pesos da administração e das engenharias somadas. Além disso, cursos especificamente voltados à área de finanças são bastante importantes. Por fim, um quinto dos cursos de outras áreas também especificam as finanças em seus nomes, por exemplo, "Economia e Finanças”, “Administração e Finanças" e "Modelos Matemáticos em Finanças".

Tabela 5 - Áreas de Conhecimento das Pós-Graduações Stricto Sensu dos Dirigentes de IF Brasileiras

\begin{tabular}{l|r|r|r|r|r|r|r|r|r}
\hline \multirow{2}{*}{ Área de Conhecimento } & \multicolumn{3}{|c|}{ Total } & \multicolumn{1}{|c|}{ IFNB } & \multicolumn{3}{|c}{ Bancos } \\
\cline { 2 - 8 } & $\mathrm{N}$ & \multicolumn{1}{|c|}{ Freq. } & Freq. Ac. & $\mathrm{N}$ & Freq. & Freq. Ac. & $\mathrm{N}$ & \multicolumn{1}{c}{ Freq. } & Freq. Ac. \\
\hline Economia & 82 & $41,8 \%$ & $41,8 \%$ & 69 & $51,9 \%$ & $51,9 \%$ & 13 & $20,6 \%$ & $20,6 \%$ \\
Administração & 27 & $13,8 \%$ & $55,6 \%$ & 13 & $9,8 \%$ & $61,7 \%$ & 14 & $22,2 \%$ & $42,9 \%$ \\
Engenharia & 16 & $8,2 \%$ & $63,8 \%$ & 12 & $9,0 \%$ & $70,7 \%$ & 4 & $6,3 \%$ & $49,2 \%$ \\
Finanças & 15 & $7,7 \%$ & $71,4 \%$ & 9 & $6,8 \%$ & $77,4 \%$ & 6 & $9,5 \%$ & $58,7 \%$ \\
Direito & 15 & $7,7 \%$ & $79,1 \%$ & 8 & $6,0 \%$ & $83,5 \%$ & 7 & $11,1 \%$ & $69,8 \%$ \\
Matemática & 9 & $4,6 \%$ & $83,7 \%$ & 6 & $4,5 \%$ & $88,0 \%$ & 3 & $4,8 \%$ & $74,6 \%$ \\
Contabilidade & 7 & $3,6 \%$ & $87,2 \%$ & 1 & $0,8 \%$ & $88,7 \%$ & 6 & $9,5 \%$ & $84,1 \%$ \\
Outras & 25 & $12,8 \%$ & $100,0 \%$ & 15 & $11,3 \%$ & $100,0 \%$ & 10 & $15,9 \%$ & $100,0 \%$ \\
\hline
\end{tabular}

Fonte: Elaboração própria.

\footnotetext{
${ }^{20}$ Não estão disponíveis muitos estudos recentes que permitam comparar esse nível de instrução formal com outras categorias de dirigentes de empresas. Além do já referido artigo de Ellersgaard et al. (2012), um dos poucos é o estudo de Dang et al. (2014) sobre os integrantes dos conselhos de administração de 120 grandes empresas francesas. Apoiando-se em dados sobre 1.250 integrantes desses conselhos retirados dos relatórios anuais das empresas referentes a 2010, encontraram uma proporção de $60 \%$ com pelo menos títulos de mestre, aí incluídos um total de $32 \%$ de doutores.
} 
Mais uma vez, há diferenças importantes entre os perfis de formação dos dirigentes de bancos e de IFNB. Primeiramente, embora o número de dirigentes de IFNB retratados na base seja cerca de $50 \%$ maior do que o de dirigentes de bancos, o número total de formações de pósgraduação stricto sensu é duas vezes maior entre aqueles do que entre estes. Há também diferenças importantes no que se refere à orientação dessas formações. Entre os dirigentes de IFNB, a formação em economia alcança a maioria absoluta; entre os de bancos, é maior a dispersão entre as áreas de conhecimento e ampliam-se as participações da administração e, em menor medida, do direito.

Foi possível identificar em quais instituições de ensino superior (IES) foram obtidas 193 das 197 pós-graduações reportadas na tabela anterior. Essas pós-graduações foram cursadas em 59 instituições de ensino diferentes. Em 31 delas, apenas um dirigente realizou pós-graduação. Mais do que isso, a concentração dos títulos nas IES que titularam mais dirigentes é maior do que no caso das graduações. Para o conjunto dos indivíduos, metade das pós-graduações foram obtidas em apenas cinco IES (Tabela A.2 em anexo). Semelhantemente ao que já se observou no tocante às áreas de conhecimento, a concentração em relação às IES é bem maior entre as IFNB do que entre os bancos. No primeiro desses segmentos, as 10 IES mais destacadas concederam $72 \%$ dos títulos de pós-graduação; no segundo, 55\%. Note-se, ademais, que as quatro instituições mais salientes no tocante às pós-graduações são as mesmas que se destacam no âmbito das graduações, mas o ranking entre elas é bem diferente. A FGV tem na pósgraduação stricto sensu importância maior, ocorrendo o contrário com USP, PUC-Rio e UFRJ.

O vínculo institucional e a nacionalidade das IES dos cursos de pós-graduação stricto sensu presentes na base de dados são retratados na Tabela 3 acima. Em síntese, esses cursos foram realizados em sua maioria $(75 \%)$ em instituições de ensino brasileiras, mas cabe recuperar que essa proporção é significativamente maior no nível das graduações (95\%). Da mesma maneira, a participação das IES públicas brasileiras é menor no âmbito das pósgraduações stricto sensu (26\%) do que nas graduações (36\%). Por outro lado, ainda que predominantes, as pós-graduações em IES privadas brasileiras (49\%) também são menos frequentes do que as respectivas graduações (60\%). Novamente, porém, o perfil das IES privadas em que se pós-graduaram os dirigentes de IF é bem diferente do usual no sistema de ensino superior brasileiro. Além das duas principais universidades católicas do País, sobressaem aqui algumas poucas instituições de elite especializadas no ensino de economia e negócios, como a FGV, o Insper e o Ibmec. A Tabela 3 mostra ainda que há duas diferenças relevantes entre os dirigentes de bancos e das IFNB no que toca às pós-graduações stricto sensu: 
entre os dirigentes de bancos são mais numerosas (i) as formações no exterior e (ii) em instituições públicas.

Em 158 das formações em nível de pós-graduação stricto sensu, o levantamento de dados conseguiu detalhar a localização da IES. De toda maneira, considerando-se também IES, como a FGV, cuja localização não foi especificada nos résumés dos dirigentes, mas que se localizam em São Paulo ou no Rio de Janeiro, o peso do eixo Rio-São Paulo atinge 68\%. Essa fração é menor do que a encontrada no caso das graduações, mas essencialmente porque nas pósgraduações stricto sensu é bem mais alta a participação de formações no exterior. Com efeito, considerando apenas as formações no País, a parcela das instituições do eixo Rio-São Paulo é efetivamente maior do que nas graduações. De modo análogo, entre as formações no exterior, cresce a importância de instituições anglo-saxãs, em particular dos EUA, mas também, em menor medida, do Reino Unido. No tocante às diferenças entre os dois segmentos do setor financeiro, nota-se, da mesma forma que no âmbito da graduação, uma preponderância de IES cariocas entre as IFNB e das paulistas entre os bancos (Figura 2).

Figura 2 - Distribuição Geográfica das IES da Pós-Graduação Stricto Sensu dos Dirigentes de IF Brasileiras

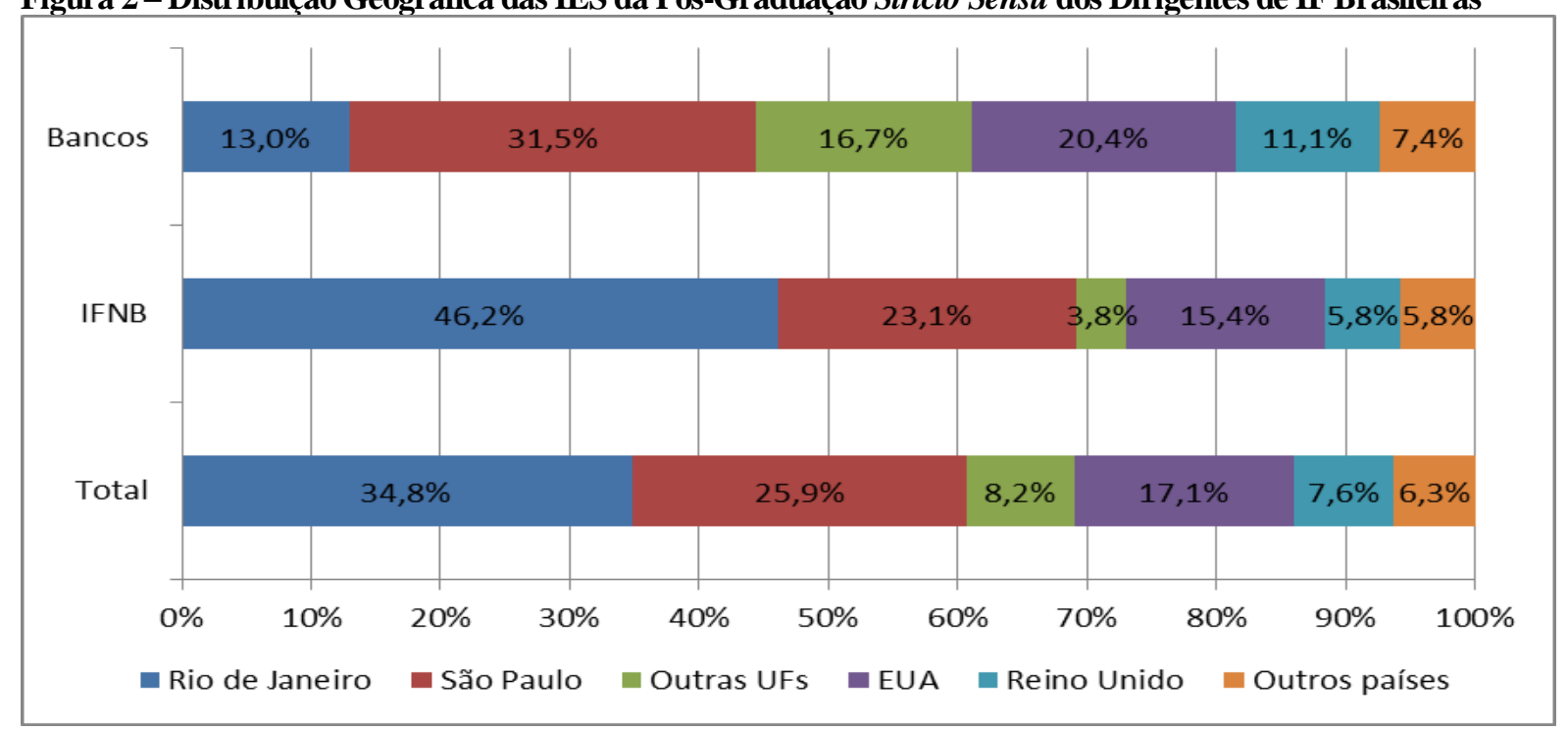

Fonte: Elaboração própria.

Cabe também avaliar as combinações de cursos e IES que mais frequentemente foram cursados pelos dirigentes de IF. As informações de maior relevo neste tema são sumariadas na Tabela 6. Embora neste caso uma avaliação mais acurada fique prejudicada pela impossibilidade de atribuir às unidades paulista ou carioca muitas das pós-graduações realizadas na FGV, é seguro afirmar que se concentram em apenas três combinações de curso e IES cerca de $30 \%$ (no mínimo $29 \%$ e no máximo 32\%) dos cursos desse nível realizados pelos 
dirigentes de IF. Como tem sido recorrente, também neste âmbito a concentração é maior entre os dirigentes de IFNB do que entre os dos bancos.

Tabela 6 - Escolas e Cursos mais Destacados na Pós-Graduação Stricto Sensu de Dirigentes de IF Brasileiras

\begin{tabular}{|c|c|c|c|c|c|c|c|c|}
\hline \multicolumn{3}{|c|}{ Total } & \multicolumn{3}{|c|}{ IFNB } & \multicolumn{3}{|l|}{ Bancos } \\
\hline IES/Área & $\mathrm{N}$ & Part. \% & IES/Área & $\mathrm{N}$ & Part. \% & IES/Área & $\mathrm{N}$ & Part.620 \\
\hline FGV/Economia & 30 & $15,6 \%$ & FGV/Economia & 28 & $20,7 \%$ & FGV/Economia & 2 & $3,3 \%$ \\
\hline PUC-Rio/Economia & 13 & $6,8 \%$ & FGV-RJ/Economia & 12 & $8,9 \%$ & USP/Economia & 2 & $3,3 \%$ \\
\hline FGV-RJ/Economia & 13 & $6,8 \%$ & PUC-RJ/Economia & 11 & $8,1 \%$ & PUC-Rio/Economia & 2 & $3,3 \%$ \\
\hline USP/Economia & 5 & $2,6 \%$ & IMPA/Matemática & 4 & $3,0 \%$ & UnB/Economia & 2 & $3,3 \%$ \\
\hline USP/Engenharia & 5 & $2,6 \%$ & USP/Engenharia & 3 & $2,2 \%$ & Oxford/Economia & 2 & $3,3 \%$ \\
\hline PUC-SP/Economia & 4 & $2,1 \%$ & USP/Economia & 3 & $2,2 \%$ & Univ. of London/Economia & 2 & $3,3 \%$ \\
\hline IMPA/Matemática & 4 & $2,1 \%$ & UFRGS/Economia & 3 & $2,2 \%$ & FGV/Administração & 2 & $3,3 \%$ \\
\hline UFRGS/Economia & 3 & $1,6 \%$ & UnB/Economia & 3 & $2,2 \%$ & USP/Administração & 2 & $3,3 \%$ \\
\hline UnB/Economia & 3 & $1,6 \%$ & Oxford/Economia & 3 & $2,2 \%$ & FGV-SP/Administração & 2 & $3,3 \%$ \\
\hline FGV/Administração & 3 & $1,6 \%$ & USP/Matemática & 3 & $2,2 \%$ & USP/Engenharia & 2 & $3,3 \%$ \\
\hline Top-10 & 83 & $43,2 \%$ & Top-10 & 73 & $54,1 \%$ & Top-10 & 20 & $33,3 \%$ \\
\hline
\end{tabular}

Fonte: Elaboração própria.

Nota: No conjunto das IF, há mais seis outros cursos com 3 pós-graduações stricto sensu: economia em Oxford, administração na FGV-RJ, administração na UFRJ, engenharia na PUC-Rio, engenharia na UFRJ e matemática na USP. De modo similar, especificamente entre os dirigentes dos bancos, contam-se duas pós-graduações stricto sensu também na engenharia da UFRJ e na contabilidade da USP.

\subsection{FORMAÇÃO DE PÓS-GRADUAÇÃO LATO SENSU}

O levantamento identificou 643 formações em nível de pós-graduação lato sensu, as quais foram divulgadas por $460(45 \%)$ dos indivíduos retratados na base de dados. O número de dirigentes que reportam mais de um curso de formação é maior neste nível de ensino do que em qualquer outro. Com efeito, 106 mencionam duas especializações e há 20 com três ou mais especializações. A comparação entre a quantidade de dirigentes de IF com pós-graduação stricto sensu e aqueles com pós-graduação lato sensu revela que estes são $164 \%$ mais numerosos.

Em relação às áreas de conhecimento cobertas neste nível de ensino, deve-se destacar primeiramente que a ausência de padronização dos nomes dos cursos tornou mais árduo o esforço para agregá-los em categorias passíveis de análise. Na base de dados, estão presentes cursos lato sensu com centenas de diferentes designações. Mais ainda do que no caso da pós stricto sensu, outra dificuldade importante foi a alta frequência de cursos cujos nomes referiamse a mais de uma área, por exemplo, "Administração e Finanças", "Controladoria e Finanças" e "Economia e Finanças". Optou-se, neste caso, por reunir na área de finanças todos os cursos que mencionassem em seus nomes termos como finanças, mercado financeiro, mercado de capitais e bancos. Já os MBAs foram classificados na área de administração, exceto nos casos em que havia referência explícita às áreas de finanças, direito ou controladoria. 
A Tabela 7 demonstra que, diferentemente do equilíbrio entre três áreas existente no âmbito da graduação e do predomínio da economia observado no nível da pós-graduação stricto sensu, administração e finanças são os dois campos amplamente majoritários nas pósgraduações lato sensu, reunindo mais de $80 \%$ das formações registradas na base de dados. Por outro lado, a principal diferença entre os dirigentes de IFNB e de bancos é que entre estes a formação em administração é mais frequente, ao passo que entre aqueles prevalece a formação em finanças. É provável que as necessidades mais variadas de organizações de maior porte, como são os bancos, induza um perfil de formação entre seus dirigentes menos concentrado em temas específicos da área financeira.

Tabela 7 - Áreas de Conhecimento das Pós-Graduações Lato Sensu dos Dirigentes de IF Brasileiras

\begin{tabular}{|c|c|c|c|c|c|c|c|c|c|}
\hline \multirow[b]{2}{*}{ Área de Conhecimento } & \multicolumn{3}{|c|}{ Total } & \multicolumn{3}{|c|}{ IFNB } & \multicolumn{3}{|c|}{ Bancos } \\
\hline & $\mathrm{N}$ & Freq. & Freq. Ac. & $\mathrm{N}$ & Freq. & Freq. Ac. & $\mathrm{N}$ & Freq. & Freq. Ac. \\
\hline Administração & 277 & $43,1 \%$ & $43,1 \%$ & 104 & $39,0 \%$ & $39,0 \%$ & 173 & $46,0 \%$ & $46,0 \%$ \\
\hline Finanças & 248 & $38,6 \%$ & $81,6 \%$ & 122 & $45,7 \%$ & $84,6 \%$ & 126 & $33,5 \%$ & 79,5 \\
\hline Direito & 18 & $2,8 \%$ & $84,4 \%$ & 6 & $2,2 \%$ & $86,9 \%$ & 12 & $3,2 \%$ & $82,7 \%$ \\
\hline Contabilic & 16 & $2,5 \%$ & $90,7 \%$ & 2 & $0,7 \%$ & $91,8 \%$ & 14 & $3,7 \%$ & $89,9 \%$ \\
\hline Economia & 14 & $2,2 \%$ & $86,6 \%$ & 7 & $2,6 \%$ & $89,5 \%$ & 7 & $1,9 \%$ & $84,6 \%$ \\
\hline Engenharia & 10 & $1,6 \%$ & $88,2 \%$ & 4 & $1,5 \%$ & $91,0 \%$ & 6 & $1,6 \%$ & $86,2 \%$ \\
\hline Outras & 60 & $9,3 \%$ & $100,0 \%$ & 22 & $8,2 \%$ & $100,0 \%$ & 38 & $10,1 \%$ & $100,0 \%$ \\
\hline
\end{tabular}

Fonte: Elaboração própria.

Foram identificadas as instituições de ensino superior (IES) em que foram cursados 587 das 643 pós-graduações reportadas na tabela anterior. São 125 instituições de ensino diferentes. Em 77 delas, um único dirigente realizou pós-graduação. Efetivamente, embora o número total de graduações seja bem superior ao de pós-graduações lato sensu, há maior dispersão das IES em que foram realizados cursos neste nível. Isso não implica, porém, que esse conjunto de IES seja pouco concentrado: oito instituições são responsáveis por mais da metade dos cursos (Tabela A.3 em anexo). Mais do que isso, reunindo todas as unidades da FGV sob uma só designação, atinge-se nada menos que um quarto de todos os cursos de pós-graduação lato sensu.

Além da singular proeminência da FGV, o ranking das principais IES neste nível de ensino apresenta outras diferenças importantes em relação ao quadro traçado para as graduações e pós-graduações stricto sensu, que, como se destacou, eram convergentes em aspectos importantes. Nas pós-graduações lato sensu, PUC-Rio e UFRJ perdem peso ${ }^{21}$. Em contrapartida, aumenta bastante a importância relativa de escolas especializadas na área de economia e negócios como o Ibmec e o Insper. Além disso, desagregando a análise, percebe-se

${ }^{21}$ No caso da USP, levando em conta fundações vinculadas a departamentos da universidade, como a Fia e a Fipecafi, isso não chega a ocorrer. 
que neste nível de ensino é menor do que nos outros a diferença entre os dirigentes de IFNB e dos bancos concernente aos níveis de concentração da formação em algumas IES. No primeiro desses segmentos, as 10 IES mais destacadas concederam $65 \%$ dos títulos de pós-graduação, pouco acima dos $60 \%$ observados no segundo. Há, no entanto, diferenças significativas na hierarquia das instituições, como se pode depreender da Tabela A.3.

Assim como nos outros níveis de ensino, as pós-graduações lato sensu cursadas em IES brasileiras predominam amplamente (79\%), ainda que essa proporção se aproxime mais da registrada na pós-graduação stricto sensu do que na graduação (Tabela 3). De outra parte, a participação das IES públicas brasileiras (12\%) é bem menor do que na pós-graduação stricto sensu (26\%) e nas graduações (36\%). Em contrapartida, alarga-se na pós-graduação lato sensu (67\%), o predomínio que as IES privadas brasileiras também ostentam na pós stricto sensu (49\%) e na graduação (60\%). Outro ponto importante nesta discussão é que, seguindo o que já foi indicado para outros atributos da formação em pós-graduações lato sensu, as diferenças entre as formações dos dirigentes de bancos e de IFNB são aqui pouco expressivas, exceto talvez pelo maior peso que as formações no exterior têm entre os dirigentes de IFNB.

Como já se disse anteriormente, o fato de os résumés dos dirigentes muitas vezes não especificarem a localização da unidade em que se formaram prejudica em certa medida a análise da distribuição especial dos cursos. O problema se acentua no caso da pós-graduação lato sensu pela já aludida liderança da FGV. Ainda assim, atribuindo-se ao eixo Rio-São Paulo cursos de instituições que operam em ambos as unidades da federação, pode-se inferir que quase 3/4 dos cursos desse nível foram realizados em um dos dois estados, o que demonstra, mais uma vez, a fortíssima concentração espacial da formação desses dirigentes (Figura 3). Repete-se também algo que já foi detectado nos outros níveis de ensino: IES cariocas predominam entre os dirigentes de IFNB e as paulistas, de forma muito mais ampla, entre os bancos. Por outro lado, entre as formações no exterior, os EUA predominam de forma contundente. Os cursos realizados nesse país correspondem a mais de $80 \%$ de todas as formações de pós-graduação lato sensu no exterior. 
Figura 3 - Distribuição Geográfica das IES da Pós-Graduação Lato Sensu dos Dirigentes de IF Brasileiras

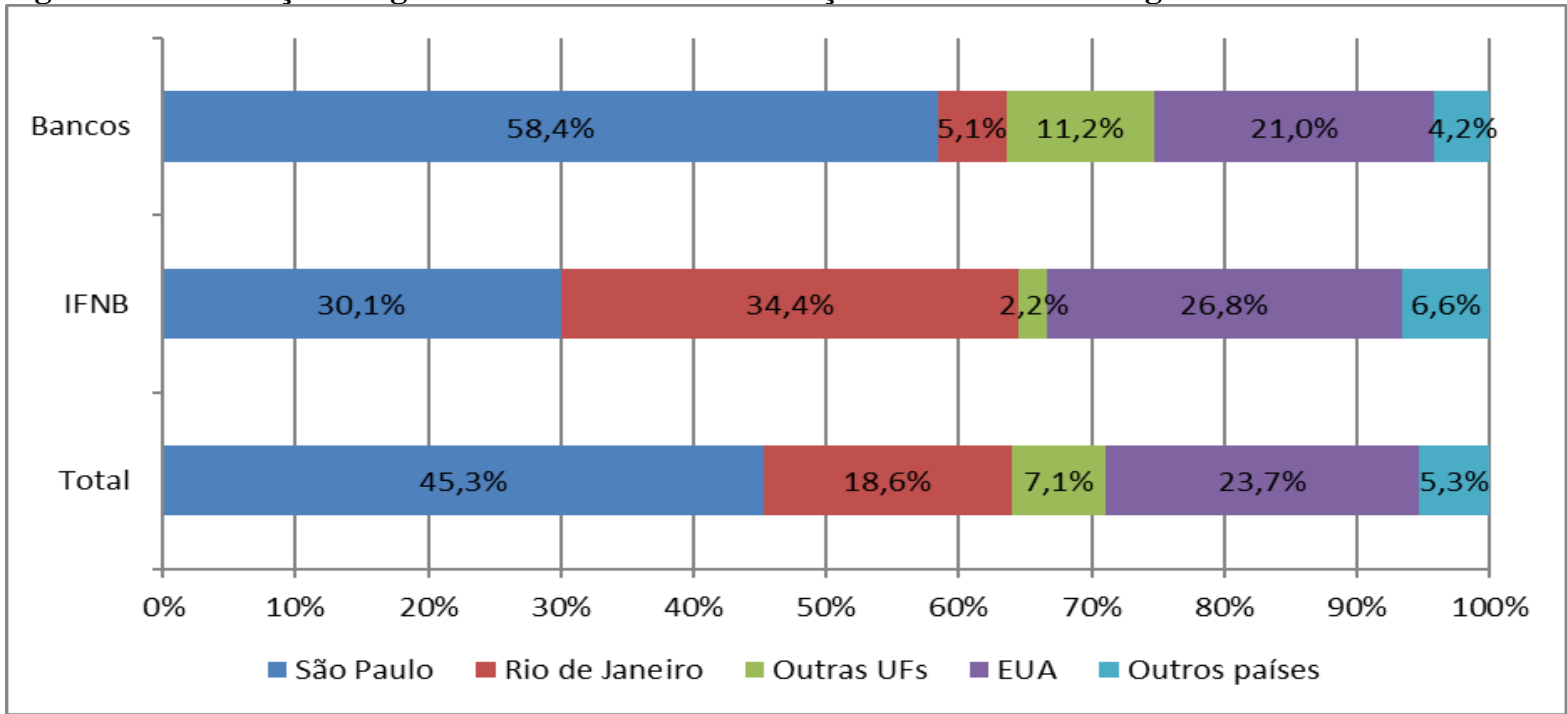

Fonte: Elaboração própria.

Finalmente, deve-se ressalvar que a diversidade dos cursos lato sensu prejudica uma análise análoga à feita nas graduações e na pós stricto sensu para as combinações de cursos e instituições. No entanto, pode-se afiançar que cursos nas áreas de administração na FGV e finanças na mesma instituição e no Ibmec são as três alternativas mais numerosas na base de dados.

\section{CONCLUSÕES}

A análise da base de dados montada a partir das informações primárias retiradas dos résumés dos dirigentes de instituições financeiras brasileiras oferece várias conclusões importantes.

A primeira delas refere-se à participação feminina, que é baixa mesmo em comparação a outras posições de elite na sociedade brasileira. A Figura 4 reúne informações que subsidiam essa comparação. A parcela de mulheres entre os dirigentes de IF é inferior à registrada em todas as instâncias da magistratura - inclusive nos tribunais de segunda instância e mesmo nos superiores -, na Câmara de Deputados e no Senado Federal. É, porém, superior àquela que o Instituto Brasileiro de Governança Corporativa (2016) encontrou em estudo sobre a composição dos conselhos de administração de empresas de capital aberto. O senso comum sugere que a baixa proporção de mulheres no mercado financeiro seria, ao menos em parte, explicável pela preferência feminina por carreiras universitárias que não são as privilegiadas pelas instituições financeiras. A relevância desse fator pode ser testada empregando-se os dados de Guedes (2008) 
sobre a parcela feminina no contingente de pessoas formadas no ano 2000 nas quatro áreas de graduação mais destacadas entre os dirigentes de IF (Tabela 2) para calcular qual a parcela de mulheres que, tudo o mais constante, seria esperada nessa categoria social. $\mathrm{O}$ valor a que se chega, $29 \%$, é mais do que o dobro do efetivamente encontrado ${ }^{22}$.

\section{Figura 4 - Participação Feminina em Posições de Elite no Brasil}

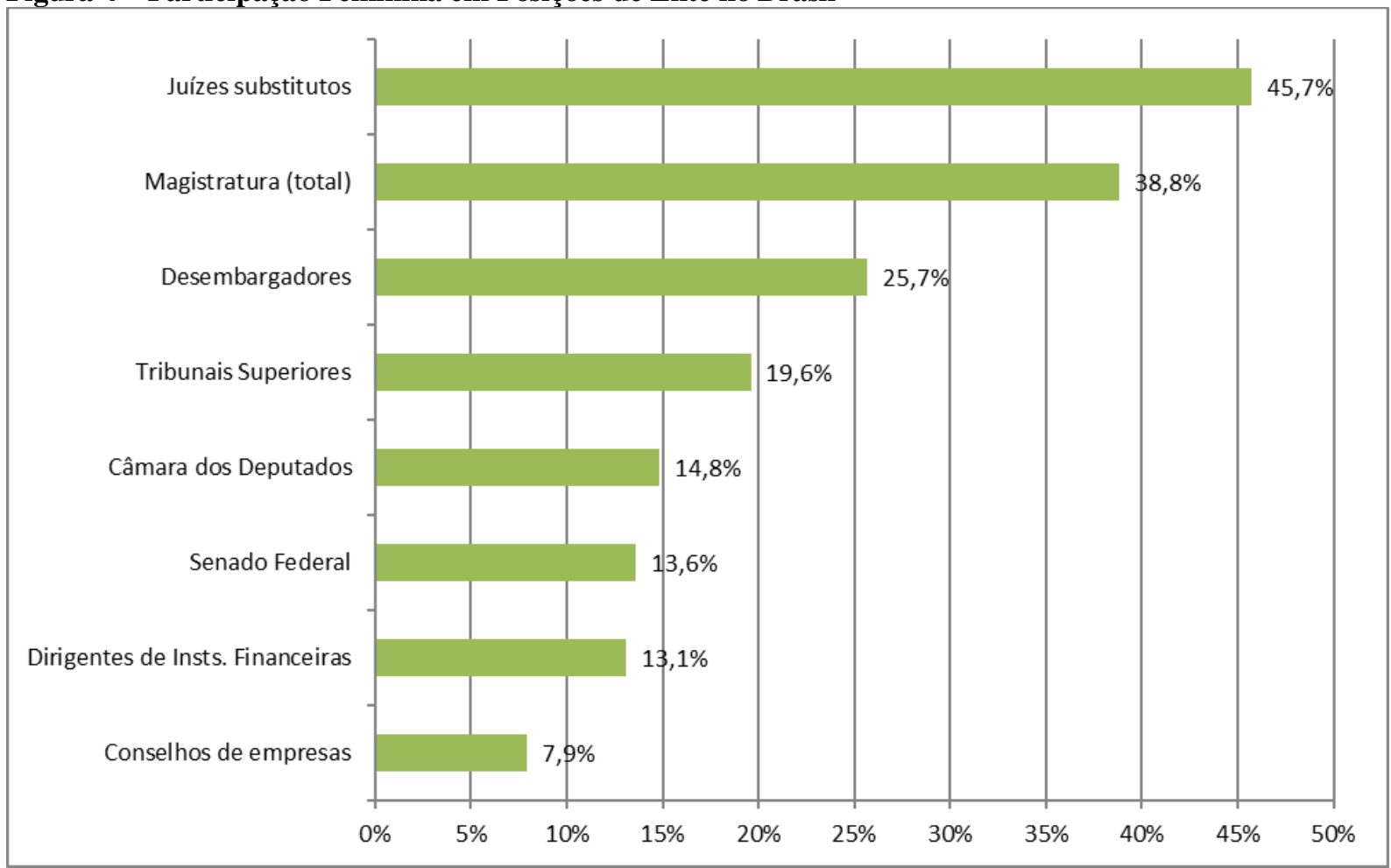

Fontes: Para os dirigentes de IF, dados de 2019 retirados da base de dados deste artigo; para as carreiras da magistratura, dados de 2018 obtidos em Conselho Nacional de Justiça (2019); para os conselhos das empresas, dados de 2016 obtidos em Instituto Brasileiro de Governança Corporativa (2016); para o Senado e a Câmara dos Deputados, dados de 2020 obtidos em Boldrini (2020).

A importância relativamente baixa das pós-graduações stricto sensu na formação dos dirigentes de IF brasileiras é outra conclusão que os dados permitem sustentar. Embora as pósgraduações lato sensu sejam bastante difundidas - ao menos $45 \%$ dos dirigentes indicam ter alguma formação nesse nível -, as pós-graduações stricto sensu são muito menos numerosas. Apenas 17\% deles teriam cursado pelo menos um mestrado e não mais que 2\%, um doutorado. Essas proporções são inferiores às observadas, por exemplo, entre os juízes brasileiros: $21 \% \mathrm{e}$ 5\%, respectivamente (CONSELHO NACIONAL DE JUSTIÇA, 2019). Conquanto não tenha

\footnotetext{
${ }^{22}$ Empregamos nesse exercício a porcentagem de mulheres no total de pessoas formadas em cada uma daquelas quatro áreas em 2000. Caso seja empregada outra proporção apresentada por Guedes (2008), a parcela de mulheres entre as pessoas formadas com idade entre 20 e 29 anos naquele ano, a participação esperada sobe para $43 \%$. Naturalmente, a diferença decorre da crescente participação feminina entre os estudantes universitários brasileiros. De acordo com os dados INEP relativos a 2018, no Brasil $61 \%$ dos concluintes nos cursos superiores eram mulheres (INEP, 2019).
} 
sido possível cotejar essas informações com as do setor financeiro em outros países, a comparação com os integrantes dos conselhos de empresas de capital aberto francesas resulta ainda mais desfavorável: $60 \%$ e 32\%, respectivamente (DANG et al., 2014).

No que concerne às áreas de conhecimento cobertas na formação dos dirigentes de IF brasileiras, há marcantes diferenças entre os vários níveis de ensino. Na graduação, quase 80\% dos dirigentes se formaram em administração, economia e engenharia, com as três áreas assumindo um peso parecido (Tabela 2). A concentração nessas três áreas é um tanto mais acentuada do que a registrada também entre os integrantes dos conselhos de administração de empresas brasileiras de capital aberto. 65\% dos conselheiros se formaram em uma das três áreas, mas com uma hierarquia que privilegia mais a engenharia (28\%) e menos a economia (16\%), além de conferir à administração uma posição intermediária (21\%) (INSTITUTO BRASILEIRO DE GOVERNANÇA CORPORATIVA, 2016, p. 19).

Na pós-graduação stricto sensu, essas mesmas áreas - se incluirmos finanças como uma formação interdisciplinar centrada em economia e administração - reúnem $71 \%$ das formações. Há, porém, neste caso um predomínio acentuado da formação em economia (41\%) (Tabela 5). Já na pós-graduação lato sensu, duas áreas se destacam claramente das demais, e administração e finanças, em proporções semelhantes, somam $82 \%$ das formações (Tabela 7).

A concentração geográfica dos cursos é outra conclusão muito clara da pesquisa. Tiveram origem no eixo Rio-São Paulo 82\% das graduações, 74\% das pós-graduações lato sensu e 68\% das pós-graduações stricto sensu. A menor proporção na pós-graduação decorre essencialmente da maior participação dos cursos no exterior. Mesmo que sempre minoritária, esta parcela se eleva em paralelo à etapa da formação: $5 \%$ na graduação, $21 \%$ na pós-graduação lato sensu e $25 \%$ na pós-graduação stricto sensu.

Com respeito ao vínculo institucional, cabe ressaltar que as formações em IES públicas não são dominantes em nenhum dos níveis de ensino. Na graduação, em particular, a parcela de 36\% dessas instituições é bem inferior à de $49 \%$ encontrada no último levantamento desse tipo feito para os juízes brasileiros (CONSELHO NACIONAL DE JUSTIÇA, 2018). Na pósgraduação stricto sensu (26\%) e, mais ainda, na pós-graduação lato sensu (12\%) essas parcelas são menores e, em contrapartida, amplia-se a predomínio das IES privadas (Tabela 3). Não é ocioso recordar, todavia, que o perfil das IES privadas que concentram a formação dos dirigentes de IF é bem diferente daquele que é mais frequente no sistema de ensino superior brasileiro. No âmbito da graduação, avultam em importância instituições confessionais, em particular pontifícias universidades católicas; nas pós-graduações, sobressai um punhado de escolas focadas nas áreas de economia e negócios, notadamente a FGV. 
Não é só em termos geográficos que a formação dos dirigentes das IF deve ser considerada concentrada. Embora o número absoluto de IES presentes na base de dados não seja pequeno, às dez mais destacadas corresponde, tanto na graduação quanto na pós-graduação, cerca de $60 \%$ do total de formações. Além disso, os dez cursos mais frequentes são responsáveis por $39 \%$ das graduações e $44 \%$ das pós-graduações stricto sensu. De todo modo, esse nível de concentração não parece suficiente para que se infira que a passagem por um grupo muito restrito de escolas é uma condição para o acesso a posições de elite no mercado financeiro brasileiro, como alguns autores sugerem que ocorre, por exemplo, com os executivos britânicos (Oxbridge) e franceses (grandes écoles) (ELLERSGAARD et al., 2012; DANG et al., 2014).

Além de analisar os dados da base para o conjunto das instituições financeiras, como se fez até aqui nesta conclusão, o artigo abordou também as diferenças entre dois grandes segmentos em que se pode dividir o setor financeiro: os bancos e as instituições financeiras não bancárias. Com a exceção parcial das pós-graduações lato sensu, a pesquisa encontrou quase que invariavelmente maior concentração das formações - seja em termos de áreas, seja de IES - no caso das IFNB, cujos dirigentes estão presentes em maior número na base de dados, do que no caso dos bancos. Explicações para esse fenômeno devem ser buscadas, primeiramente, na maior diversidade interna do segmento dos bancos. É maior a dispersão geográfica das suas sedes e, sobretudo, das suas operações. É maior também a variedade de estruturas de controle do capital, incluindo o controle estatal de bancos nacionais, regionais e estaduais. Além disso, apesar de serem maiores as barreiras à entrada no negócio bancário, os bancos tendem, por seu próprio porte e diversidade operacional, a contemplar uma maior variedade de carreiras internas às organizações. É possível também que o peso de posições de direção ocupadas por herdeiros seja diferente entre os dois segmentos, mas esta é uma questão sobre a qual a base de dados explorada neste artigo nada permite afirmar.

A incapacidade de discriminar herdeiros, como de resto acionistas em geral, no conjunto dos dirigentes de IF é uma das lacunas de um artigo que se baseou nas informações publicadas pelas próprias instituições em seus sites na internet. Outras lacunas deste artigo, porém, decorrem de opções metodológicas que não são incontornáveis. Assim, outros trabalhos poderão explorar na base de dados recortes analíticos diferentes, baseados seja em atributos das IF, como porte da empresa e natureza do controle do capital, seja em atributos dos dirigentes, como gênero, cargo ocupado e posição executiva ou consultiva. A base de dados registra também informações sobre a trajetória profissional prévia de cada dirigente, o que permite, em princípio, usar o instrumental de redes sociais para avaliar o conjunto de relações entre as IF 
subjacentes a essas trajetórias ${ }^{23}$. Por fim, as informações presentes na base podem ser empregadas para análises calcadas na Upper Echelons Theory, buscando identificar associações entre características dos dirigentes e o desempenho das instituições por eles dirigidas. Conquanto tais análises estejam além do escopo deste artigo, a montagem da base de dados e a caracterização aqui apresentadas são etapas prévias indispensáveis para essa linha de investigação.

\section{REFERÊNCIAS}

ALMEIDA, F. N. R. A nobreza togada: as elites jurídicas e a política da Justiça no Brasil. Tese (Doutorado em Ciência Política) - Faculdade de Filosofia, Letras e Ciências Humanas, Universidade de São Paulo, 2010.

ANDERSON, R. C.; REEB, D. M.; UPADHYAY, A; ZHAO, W. The economics of director heterogeneity. Financial Management, v. 40, n. 1, p. 5-38, 2011.

ANDRADE, L. P.; SAlAZAR, G. T.; CALEGÁRIO, C. L. L.; SILVA, S. S. Governança corporativa: uma análise da relação do conselho de administração com o valor de mercado e desempenho das empresas brasileiras. Revista de Administração Mackenzie, v. 10, n. 4, p. 4$31,2009$.

ARANHA, C. E.; ROSSONI, L.; MENDES-DA-SILVA, W. Capital social do conselho de administração e desempenho das empresas de capital aberto brasileiras. Revista de Administração Mackenzie, v. 17, n. 1, p. 15-39, 2016.

ARAÚJO, P. M. Recrutamento parlamentar para o Senado e o perfil dos senadores brasileiros: 1989-2006. Política Hoje, v. 20, n. 2, p. 550-580, 2011.

ARON, R. Social structure and the ruling class: part 1. British Journal of Sociology, v. 1, n. 2, p. 126-43, 1950.

\footnotetext{
${ }^{23}$ A esse respeito pode-se antecipar que o Banco BTG Pactual parece ter uma posição central na atua rede de formação profissional dos dirigentes de IF no Brasil: excluindo-se os que atuavam naquele momento no próprio banco, tinham passado pelo BTG Pactual nada menos que 72 dos 757 dirigentes que apresentavam informações sobre experiência prévia em seus résumés.
}

(c) (1) $\Theta$ REAd | Porto Alegre - Vol. 27 - N.o 2 - Maio / Agosto 2021 - p. 612-641. 
BOLDRINI, A. Bancada feminina amplia presença em postos de poder, mas desigualdade persiste no Congresso. Folha de São Paulo, São Paulo, 8 mar. 2020. Disponível em $<$ https://www1.folha.uol.com.br/poder/2020/03/bancada-feminina-amplia-presenca-empostos-de-poder-mas-desigualdade-persiste-no-congresso.shtml>. Acesso em 8 mar. 2020.

CAMILO, S. P. O.; MARCON, R.; BANDEIRA-DE-MELLO, R. Conexões políticas e desempenho: um estudo das firmas listadas na BM\&FBovespa. Revista de Administração Contemporânea, v. 16, n. 6, p. 806-826, 2012.

CONSELHO NACIONAL DE JUSTIÇA. Perfil sociodemográfico dos magistrados brasileiros - 2018. Brasília, Departamento de Pesquisas Judiciárias / Conselho Nacional de Justiça, 32 p., 2018.

COSTA, L. D.; CODATO, A. Profissionalização ou popularização da classe política brasileira? Um perfil dos senadores da República. In: MARENCO, A. (org.) Os Eleitos: representação e carreiras políticas em democracias. Porto Alegre: Editora da UFRGS, p. 107-134, 2013.

COSTA, P. R. N. Elite empresarial e elite econômica: o estudo dos empresários. Revista de Sociologia e Política, v. 22, n. 52, p. 47-57, 2014.

COSTA, L.; SAMPAIO, J. O.; FLORES, E. S. Diversidade de gênero nos conselhos administrativos e sua relação com desempenho e risco financeiro nas empresas familiares. Revista de Administração Contemporânea, v. 23, n. 6, p. 721-738, 2019.

COUSIN, B.; KHAN, S.; MEARS, A. Theoretical and methodological pathways for research on elites. Socio-Economic Review, v. 16, n. 2, p. 225-249, 2018.

DANG, R.; BENDER, A.-F.; SCOTTO, M.-J. Women on French corporate board of directors: how do they differ from their male counterparts? The Journal of Applied Business Research, v. 30, n. 2, p. 489-508, 2014.

ELLERSGAARD, C. H.; LARSEN, A. G.; MUNK, M. D. A very economic elite: the case of the Danish top CEOs. Sociology, v. 0, n. 0, p. 1-21, 2012.

GUEDES, M. C. A presença feminina nos cursos universitários e nas pós-graduações: desconstruindo a ideia da universidade como espaço masculino. História, Ciências, Saúde Manguinhos, v. 15, supl., p. 117-132, 2008.

(c) (1) $($ REAd | Porto Alegre - Vol. 27 - N.o 2 - Maio / Agosto 2021 - p. 612-641. 
HAGENDORFF, J.; KEASEY, K. The value of board diversity in banking: evidence from the market for corporate control. The European Journal of Finance, v. 18, n. 1, p. 41-58, 2010.

HAMBRICK, D. C.; MASON, P. A. Upper echelons: the organization as a reflection of its top managers. The Academy of Management Review, v. 9, n. 2, p. 193-206, 1984.

INSTITUTO BRASILEIRO DE GOVERNANÇA CORPORATIVA. Perfil dos Conselhos de Administração. São Paulo, Instituto Brasileiro de Governança Corporativa, 43p., 2016.

INEP. Sinopse Estatística da Educação Superior - 1994. Brasília: Instituto Nacional de Estudos e Pesquisas Educacionais Anísio Teixeira. Disponível em http://inep.gov.br/sinopsesestatisticas-da-educacao-superior, acesso em 4 mar. 2020., 1995.

INEP. Sinopse Estatística da Educação Superior - 2018. Brasília: Instituto Nacional de Estudos e Pesquisas Educacionais Anísio Teixeira. Disponível em http://portal.inep.gov.br/basica-censo-escolar-sinopse-sinopse, acesso em 4 mar. 2020, 2019.

JOHNSON, S. G.; SCHNATTERLY, K.; HILL, A. D. Board composition beyond independence: social capital, human capital, and demographics. Journal of Management, v. 39, n. 1, p. 232-262, 2013.

LOUREIRO, M. R.; ABRUCIO, F.; ROSA, C. A. Radiografia da alta burocracia federal brasileira: o caso do Ministério da Fazenda. Revista do Serviço Público, v. 49, n. 4, p. 46-82, 1998.

LOUREIRO, M. R.; OLIVIERI, C. Les élites économiques face au développement et à la démocracie: les patrons et les hauts fonctionnaires du gouvernement ao Brésil. Cahiers du Brésil Contemporain, n. 47/48, p. 267-289, 2002.

MARKOWITZ, M. A. Bancos e banqueiros: empresas e famílias no Brasil. Dissertação (Mestrado em Antropologia Social) - Museu Nacional, Universidade Federal do Rio de Janeiro, 2004.

RAMOS, M. M.; CASTRO, F. A. Aristocracia judicial brasileira: privilégios, habitus e cumplicidade estrutural. Revista Direito GV, v. 15, n. 2, p. 1-36, 2019. 
STONE, L. Prosopografia. Revista de Sociologia e Política, v. 19, n. 39, p. 115-137, 2011

[Tradução de Gustavo B. Lacerda e Renato M. Perissinotto do original: Stone, L. Prosopography. Dædelus, v. 100, n. 1, p. 46-79, 1971]. 


\section{ANEXO}

Tabela A.1 - IES mais Destacadas na Graduação de Dirigentes de IF Brasileiras

\begin{tabular}{|c|c|c|c|c|c|c|}
\hline \multirow[b]{2}{*}{ Instituição de Ensino } & \multicolumn{2}{|c|}{ Total } & \multicolumn{2}{|c|}{ IFNB } & \multicolumn{2}{|c|}{ Bancos } \\
\hline & $\mathrm{N}$ & Part. & $\mathrm{N}$ & Part. & $\mathrm{N}$ & Part. \\
\hline PUC-Rio & 142 & $14,8 \%$ & 127 & $21,9 \%$ & 15 & $4,0 \%$ \\
\hline USP & 136 & $14,2 \%$ & 82 & $14,1 \%$ & 54 & $14,3 \%$ \\
\hline UFRJ & 67 & $7,0 \%$ & 58 & $10,0 \%$ & 9 & $2,4 \%$ \\
\hline FGV & 53 & $5,5 \%$ & 40 & $6,9 \%$ & 13 & $3,4 \%$ \\
\hline PUC-SP & 39 & $4,1 \%$ & 20 & $3,4 \%$ & 19 & $5,0 \%$ \\
\hline FAAP & 29 & $3,0 \%$ & 14 & $2,4 \%$ & 15 & $4,0 \%$ \\
\hline Universidade Candido Mendes & 25 & $2,6 \%$ & 21 & $3,6 \%$ & 4 & $1,1 \%$ \\
\hline Ibmec-RJ & 22 & $2,3 \%$ & 22 & $3,8 \%$ & 0 & $0,0 \%$ \\
\hline Mackenzie & 21 & $2,2 \%$ & 11 & $1,9 \%$ & 10 & $2,7 \%$ \\
\hline ITA & 19 & $2,0 \%$ & 11 & $1,9 \%$ & 8 & $2,1 \%$ \\
\hline Ibmec & 15 & $1,6 \%$ & 12 & $2,1 \%$ & 3 & $0,8 \%$ \\
\hline Unicamp & 14 & $1,5 \%$ & 5 & $0,9 \%$ & 9 & $2,4 \%$ \\
\hline UERJ & 13 & $1,4 \%$ & 9 & $1,6 \%$ & 4 & $1,1 \%$ \\
\hline FMU & 13 & $1,4 \%$ & 4 & $0,7 \%$ & 9 & $2,4 \%$ \\
\hline UNIP & 13 & $1,4 \%$ & 2 & $0,3 \%$ & 11 & $2,9 \%$ \\
\hline FGV-SP & 12 & $1,3 \%$ & 10 & $1,7 \%$ & 2 & $0,5 \%$ \\
\hline UFRGS & 11 & $1,1 \%$ & 5 & $0,9 \%$ & 6 & $1,6 \%$ \\
\hline UFF & 9 & $0,9 \%$ & 8 & $1,4 \%$ & 1 & $0,3 \%$ \\
\hline Insper & 9 & $0,9 \%$ & 7 & $1,2 \%$ & 2 & $0,5 \%$ \\
\hline FEI & 9 & $0,9 \%$ & 2 & $0,3 \%$ & 7 & $1,9 \%$ \\
\hline UnB & 9 & $0,9 \%$ & 2 & $0,3 \%$ & 7 & $1,9 \%$ \\
\hline UFPE & 8 & $0,8 \%$ & 2 & $0,3 \%$ & 6 & $1,6 \%$ \\
\hline UGF & 6 & $0,6 \%$ & 3 & $0,5 \%$ & 3 & $0,8 \%$ \\
\hline UFC & 6 & $0,6 \%$ & 1 & $0,2 \%$ & 5 & $1,3 \%$ \\
\hline UFMG & 5 & $0,5 \%$ & 4 & $0,7 \%$ & 1 & $0,3 \%$ \\
\hline Universidade Estácio de Sá & 5 & $0,5 \%$ & 3 & $0,5 \%$ & 2 & $0,5 \%$ \\
\hline Universidade Santa Úrsula & 5 & $0,5 \%$ & 3 & $0,5 \%$ & 2 & $0,5 \%$ \\
\hline FAE & 5 & $0,5 \%$ & 0 & $0,0 \%$ & 5 & $1,3 \%$ \\
\hline Unesp & 5 & $0,5 \%$ & 0 & $0,0 \%$ & 5 & $1,3 \%$ \\
\hline Outras 160 IES & 232 & $24,2 \%$ & 92 & $15,9 \%$ & 140 & $37,1 \%$ \\
\hline
\end{tabular}

Fonte: Elaboração própria. 
Tabela A.2 - IES mais Destacadas na Pós-Graduação Stricto Sensu de Dirigentes de IF Brasileiras

\begin{tabular}{l|r|r|r|r|r|r}
\hline \multirow{2}{*}{ Instituição de Ensino } & \multicolumn{2}{|c|}{ Total } & \multicolumn{2}{c|}{ IFNB } & \multicolumn{2}{c}{ Bancos } \\
\cline { 2 - 7 } & $\mathrm{N}$ & \multicolumn{1}{c}{ Part. } & $\mathrm{N}$ & \multicolumn{1}{c}{ Part. } & \multicolumn{1}{c}{$\mathrm{N}$} & \multicolumn{1}{c}{ Part. } \\
\hline FGV & 33 & $17,1 \%$ & 29 & $21,8 \%$ & 4 & $6,7 \%$ \\
USP & 22 & $11,4 \%$ & 11 & $30,1 \%$ & 11 & $18,3 \%$ \\
PUC-Rio & 21 & $10,9 \%$ & 18 & $43,6 \%$ & 3 & $5,0 \%$ \\
FGV-RJ & 16 & $8,3 \%$ & 14 & $54,1 \%$ & 2 & $3,3 \%$ \\
UFRJ & 8 & $4,1 \%$ & 6 & $58,6 \%$ & 2 & $3,3 \%$ \\
PUC-SP & 7 & $3,6 \%$ & 3 & $60,9 \%$ & 4 & $6,7 \%$ \\
IMPA & 5 & $2,6 \%$ & 5 & $64,7 \%$ & 0 & $0,0 \%$ \\
Insper & 4 & $2,1 \%$ & 4 & $67,7 \%$ & 0 & $0,0 \%$ \\
Ibmec-RJ & 3 & $1,6 \%$ & 3 & $69,9 \%$ & 0 & $0,0 \%$ \\
UFRGS & 3 & $1,6 \%$ & 3 & $72,2 \%$ & 0 & $0,0 \%$ \\
UnB & 3 & $1,6 \%$ & 1 & $72,9 \%$ & 2 & $3,3 \%$ \\
Oxford University & 3 & $1,6 \%$ & 1 & $73,7 \%$ & 2 & $3,3 \%$ \\
Stanford University & 3 & $1,6 \%$ & 2 & $75,2 \%$ & 1 & $1,7 \%$ \\
University of London & 3 & $1,6 \%$ & 1 & $75,9 \%$ & 2 & $3,3 \%$ \\
Outras 45 IES & 59 & $30,6 \%$ & 33 & $100,0 \%$ & 27 & $45,0 \%$ \\
\hline
\end{tabular}

Fonte: Elaboração própria.

Tabela A.3 - IES mais Destacadas na Pós-Graduação Lato Sensu de Dirigentes de IF Brasileiras

\begin{tabular}{l|r|r|r|r|r|r}
\hline \multirow{2}{*}{ Instituições de Ensino } & \multicolumn{2}{|c}{ Total } & \multicolumn{2}{c|}{ IFNB } & \multicolumn{2}{c}{ Bancos } \\
\cline { 2 - 7 } \multicolumn{1}{c|}{ FGV } & \multicolumn{1}{|c|}{ Part. } & \multicolumn{1}{c}{ P } & \multicolumn{1}{c}{ Part. } & \multicolumn{1}{c}{ Part. } \\
\hline USP & 110 & $18,7 \%$ & 49 & $19,2 \%$ & 61 & $18,4 \%$ \\
Ibmec & 42 & $7,2 \%$ & 16 & $6,3 \%$ & 26 & $7,8 \%$ \\
Insper & 35 & $6,0 \%$ & 15 & $5,9 \%$ & 20 & $6,0 \%$ \\
PUC-Rio & 28 & $4,8 \%$ & 11 & $4,3 \%$ & 17 & $5,1 \%$ \\
FGV-SP & 25 & $4,3 \%$ & 22 & $8,6 \%$ & 3 & $0,9 \%$ \\
FDC & 21 & $3,6 \%$ & 5 & $2,0 \%$ & 16 & $4,8 \%$ \\
FIA & 21 & $3,6 \%$ & 0 & $0,0 \%$ & 21 & $6,3 \%$ \\
FGV-RJ & 20 & $3,4 \%$ & 5 & $2,0 \%$ & 15 & $4,5 \%$ \\
Ibmec-RJ & 17 & $2,9 \%$ & 14 & $5,5 \%$ & 3 & $0,9 \%$ \\
Ibmec-SP & 14 & $2,4 \%$ & 14 & $5,5 \%$ & 0 & $0,0 \%$ \\
UFRJ & 13 & $2,2 \%$ & 6 & $2,4 \%$ & 7 & $2,1 \%$ \\
Harvard Business School & 10 & $1,7 \%$ & 9 & $3,5 \%$ & 1 & $0,3 \%$ \\
FIPECAFI & 10 & $1,7 \%$ & 9 & $3,5 \%$ & 1 & $0,3 \%$ \\
Mackenzie & 10 & $1,7 \%$ & 1 & $0,4 \%$ & 9 & $2,7 \%$ \\
FAAP & 9 & $1,5 \%$ & 5 & $2,0 \%$ & 4 & $1,2 \%$ \\
University of Michigan & 9 & $1,5 \%$ & 3 & $1,2 \%$ & 6 & $1,8 \%$ \\
The Wharton School & 8 & $1,4 \%$ & 5 & $2,0 \%$ & 3 & $0,9 \%$ \\
INSEAD & 7 & $1,2 \%$ & 2 & $0,8 \%$ & 5 & $1,5 \%$ \\
Stanford University & 6 & $1,0 \%$ & 2 & $0,8 \%$ & 4 & $1,2 \%$ \\
Outras 105 IES & 6 & $1,0 \%$ & 2 & $0,8 \%$ & 4 & $1,2 \%$ \\
\hline
\end{tabular}

Fonte: Elaboração própria. 